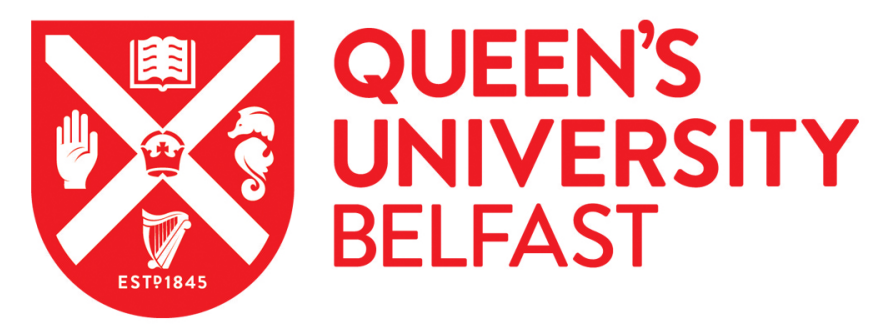

\title{
Shape stabilised phase change materials based on a high melt viscosity HDPE and paraffin waxes
}

Mu, M., Basheer, P. A. M., Sha, W., Bai, Y., \& McNally, T. (2016). Shape stabilised phase change materials based on a high melt viscosity HDPE and paraffin waxes. Applied Energy, 162, 68-82.

https://doi.org/10.1016/j.apenergy.2015.10.030

\section{Published in:}

Applied Energy

\section{Document Version:}

Peer reviewed version

\section{Queen's University Belfast - Research Portal:}

Link to publication record in Queen's University Belfast Research Portal

\section{Publisher rights}

(c) 2016 Elsevier Ltd.

This manuscript version is made available under the CC-BY-NC-ND 4.0 license http://creativecommons.org/licenses/by-nc-nd/4.0/ which permits distribution and reproduction for non-commercial purposes, provided the author and source are cited.

\section{General rights}

Copyright for the publications made accessible via the Queen's University Belfast Research Portal is retained by the author(s) and / or other copyright owners and it is a condition of accessing these publications that users recognise and abide by the legal requirements associated with these rights.

Take down policy

The Research Portal is Queen's institutional repository that provides access to Queen's research output. Every effort has been made to ensure that content in the Research Portal does not infringe any person's rights, or applicable UK laws. If you discover content in the Research Portal that you believe breaches copyright or violates any law, please contact openaccess@qub.ac.uk. 


\section{Shape stabilised phase change materials based on a high melt viscosity HDPE and paraffin waxes}

Mulan $\mathrm{Mu}^{1}$, P.A.M. Basheer ${ }^{2}$, Wei Sha ${ }^{1}$, Yun Bai ${ }^{3}$ and Tony McNally ${ }^{4 *}$

${ }^{1}$ School of Planning, Architecture \& Civil Engineering, Queen's University Belfast, BT9 $5 A G, U K$

${ }^{2}$ School of Civil Engineering, University of Leeds, LS2 9JT, UK

${ }^{3}$ Department of Civil, Environmental \& Geomatic Engineering, University College London, WC1E 6BT, UK

${ }^{4}$ International Institute for Nanocomposites Manufacturing (IINM), WMG, University of Warwick, CV4 7AL, UK

Corresponding Author: Tony McNally (t.mcnally@warwick.ac.uk) 


\begin{abstract}
Shape stabilised phase change materials (SSPCMs) based on a high density poly(ethylene)(hv-HDPE) with high $\left(\mathrm{H}-\mathrm{PW}, \mathrm{T}_{\mathrm{m}}=56-58{ }^{\circ} \mathrm{C}\right)$ and low $\left(\mathrm{L}-\mathrm{PW}, \mathrm{T}_{\mathrm{m}}=18-23{ }^{\circ} \mathrm{C}\right)$ melting point paraffin waxes were readily prepared using twin-screw extrusion. The thermophysical properties of these materials were assessed using a combination of techniques and their suitability for latent heat thermal energy storage (LHTES) assessed. The melt processing temperature $\left(160^{\circ} \mathrm{C}\right)$ of the HDPE used was well below the onset of thermal decomposition of H-PW $\left(220{ }^{\circ} \mathrm{C}\right)$, but above that for L-PW $\left(130{ }^{\circ} \mathrm{C}\right)$, although the decomposition process extended over a range of $120^{\circ} \mathrm{C}$ and the residence time of L-PW in the extruder was $<30$ seconds. The SSPCMs prepared had latent heats up to $89 \mathrm{~J} / \mathrm{g}$ and while the enthalpy values for $\mathrm{H}-\mathrm{PW}$ in the respective blends decreased with increasing H-PW loading, as a consequence of co-crystallisation of H-PW and hv-HDPE. Static and dynamic mechanical analysis confirmed both waxes have a plasticisation effect on this HDPE. Irrespective of the mode of deformation (tension, flexural, compression) modulus and stress decreased with increased wax loading in the blend, but the H-PW blends were mechanically superior to those with L-PW.
\end{abstract}




\section{Introduction}

Thermal energy storage through the use of phase change materials (PCMs) in building applications has attracted much attention recently, their use having the potential to improve energy efficiency in buildings [1-3]. PCMs are substances with a high heat of fusion, which on changing phase over a certain temperature window are capable of storing and releasing large amounts of energy. The most effective method of storing thermal energy is via latent heat, which can be given by:

$$
Q=\int_{T_{i}}^{T_{m}} m C_{p} \cdot d T+m a_{m} \cdot \Delta H_{m}+\int_{T_{m}}^{T_{f}} m C_{p} \cdot d T
$$

where, $\mathrm{Q}=$ the quantity of heat stored, $\mathrm{T}_{\mathrm{m}}=$ melting temperature, $\mathrm{T}_{\mathrm{i}}=$ initial temperature, $\mathrm{T}_{\mathrm{f}}=$ final temperature, $\mathrm{m}=$ mass of storage medium, $\mathrm{a}_{\mathrm{m}}=$ fraction of material melted, $\Delta \mathrm{H}_{\mathrm{m}}=$ heat of melting per unit mass $(\mathrm{J} / \mathrm{kg})$ and $\mathrm{C}_{\mathrm{p}}=$ specific heat capacity $(\mathrm{J} / \mathrm{kg} / \mathrm{K})$. This process creates the opportunity for utilising renewable natural energy, such as solar energy and night ventilation by incorporating PCMs into buildings [4-7]. Many different types of PCMs have been studied, such as those based on hydrated salts, paraffin, fatty acids and polyols [8-11]. Paraffin is the most attractive PCM used in buildings as it is one of the cheapest and most readily available, being derived from petroleum and having relatively good thermo-physical properties, such as high latent heat, negligible super-cooling and a suitable transition point [12]. A paraffin wax consists typically of a mixture of hydrocarbon molecules, $\mathrm{C}_{n} \mathrm{H}_{2 n+2}(n=1-100)$, with each specific wax having a range of about 8 to 15 carbon numbers. Latent heat is stored as a consequence of the crystallisation of these hydrocarbon molecules. With a melting point adjustable to climate specific requirements, the length of the hydrocarbon chain dictates both the melting point of the PCM and the heat of fusion. Hydrocarbon waxes have a wide range of melting temperatures, from $-5{ }^{\circ} \mathrm{C}$ to $61^{\circ} \mathrm{C}$ [13]. This when combined with their high heats of fusion, up to $266 \mathrm{~J} / \mathrm{g}$, makes them suitable for space heating applications. 
However, it cannot be used in buildings directly as the phase changes of paraffin waxes are between the solid and liquid states. To overcome this, researchers have developed shape stable phase change materials (SSPCMs), which use certain polymers as a supporting matrix and paraffin wax as the functional core material. By melting and mixing polymer and wax together, the polymer can form a three dimensional network structure to envelop the wax. The melting point of the polymer is always higher than that of the paraffin wax. Thus, when paraffin wax changes from solid to liquid, the supporting matrix remains solid and the paraffin wax will not leak, although there may be seepage with time, from the polymer network structure $[9,14]$. The composite material, therefore, can be used as laminated SSPCM wallboards with no need to incorporate them into building materials. A range of polymers can be used as the structural supporting component/matrix, including high- (HDPE), low- (LDPE) and linear low-density (LLDPE) poly(ethylene), styrene-butadiene-styrene (SBS) tri-block copolymer and poly(propylene) (PP), although the poly(ethylene) family have been most widely studied for SSPCM application with paraffin waxes, due to their similar chemical structures [15-19].

Inaba and Hu proposed, more than 15 years ago, the concept of HDPE/wax blends as a new type of SSPCM by melting and mixing paraffin and HDPE for thermal energy storage applications without encapsulation and determining the thermo-physical properties of the blend. The blend was composed of 26\% HDPE and 74\% paraffin by weight. The wax used consisted mainly of pentacosane $\left(\mathrm{C}_{25} \mathrm{H}_{52}, \mathrm{~T}_{\mathrm{m}}=54.2^{\circ} \mathrm{C}\right)$ [9]. Lee and Choi studied the durability of SSPCMs by investigating the seepage behaviour of a paraffin $\left(\mathrm{C}_{24} \mathrm{H}_{50}\right)$ [20]. The SSPCMs based on this paraffin wax with two different types of HDPE were prepared by simple physical mixing at a paraffin content of $70 \mathrm{wt} \%$. The authors reported the effect of HDPE crystalline morphology on the seepage behaviour of the paraffin and concluded that a higher molecular weight HDPE was required for better sealant properties. Blends of six types of HDPE with varying melt indices and paraffins were evaluated as candidate materials for SSPCMs by Hong 
and Ge [14]. The HDPEs were mixed (detail not given) with refined or semi-refined paraffin waxes of different melting points (the $T_{m}$ of the waxes was not reported) at wax contents as high as $75 \mathrm{wt} \%$. The authors showed a SSPCM based on a HDPE with a MFI=11 g/10min and semi-refined paraffin which could be used in LHTES applications. Zhang et al. developed SSPCMs for building applications using paraffin waxes having $\mathrm{T}_{\mathrm{m}}=20^{\circ} \mathrm{C}$ and $60{ }^{\circ} \mathrm{C}$ as the PCM, but studied SBS as well as HDPE as the supporting matrix [21]. The authors explored strategies to enhance the thermal conductivity of these systems by adding graphite or carbon fibre and reduce leakage of the wax from the matrix by employing surface treatments, e.g. grafting or cross-linking. However, the authors provided no information about the influence of different waxes, polymer matrices or additives on the mechanical properties of the SSPCM blends. Kaygusuz and Sari investigated the thermal properties of an SSPCM based on HDPE and four different types of waxes with $\mathrm{T}_{\mathrm{m}}=42-44{ }^{\circ} \mathrm{C}, 48-50{ }^{\circ} \mathrm{C}, 56-58{ }^{\circ} \mathrm{C}$, and $63-65{ }^{\circ} \mathrm{C}[22$, 23]. They found that the mass fraction of paraffin wax in the SSPCM could be as high as $77 \%$ without any seepage of the paraffin, for the conditions tested. The thermal conductivity of the SSPCMs, although from a low level, was improved by as much as $52 \%$ on addition of exfoliated graphite at a loading of $3 \mathrm{wt} \%$. Hato and Luyt studied the influence of wax type and content on miscibility when blended with HDPE, LDPE and LLDPE [24]. All three polymers were initially melt-mixed with a hard wax (H1), $\left(\mathrm{T}_{\mathrm{m}}=59.4{ }^{\circ} \mathrm{C}\right)$ and an oxidised wax (A1) $\left(\mathrm{T}_{\mathrm{m}}=55.4^{\circ} \mathrm{C}\right)$ in a Brabender Plastograph (screw speed $=30 \mathrm{rpm}$ for $15 \mathrm{~min}$ ). Interestingly, all HDPE/wax blends were completely miscible at both $10 \mathrm{wt} \%$ and $20 \mathrm{wt} \%$ wax content, but only partially miscible when $30 \mathrm{wt} \%$ wax was added. LDPE/hard paraffin wax blends were partially miscible at all wax loadings investigated, while only completely miscible for a low loading of $10 \mathrm{wt} \%$ oxidised wax. Complete miscibility was observed for all the LLDPE/oxidised wax blends. Further work by the same group on SSPCMs consisting of HDPE, alkali-treated wood flour (WF) and either M3 or H1 waxes (where M3 wax has $\mathrm{T}_{\mathrm{m}}=40-60^{\circ} \mathrm{C}$, average $\mathrm{M}_{\mathrm{w}}=440$ 
gmol $^{-1}$; for $\mathrm{H} 1, \mathrm{~T}_{\mathrm{m}}=107^{\circ} \mathrm{C}$, average $\mathrm{M}_{\mathrm{w}}=785 \mathrm{~g} \mathrm{~mol}^{-1}$ ) explored the effectiveness of WF in improving the mechanical properties and thermal stability of the SSPCM [25, 26]. Poor filler dispersion and interfacial adhesion were observed between the WF particles and HDPE matrix. Partial miscibility of the HDPE with both M3/H1 waxes was observed, with the WF particles covered by wax. The presence of either wax (M3 or H1) reduced the thermal stability and mechanical properties of all blends. With regard to the use of these SSPCMs in building applications increased M3 wax content resulted in a decrease in water uptake. Yan et al. prepared SSPCMs based on HDPE with four different types of waxes with $\mathrm{T}_{\mathrm{m}}$ between $21^{\circ} \mathrm{C}$ and $27^{\circ} \mathrm{C}$ and up to $70 \%$ mass content [28]. The SSPCMs prepared had large latent heats, up to $177 \mathrm{~J} / \mathrm{g}$ and were good candidates for LHTES. Co-crystallisation of paraffin waxes with poly(ethylene)s must also be considered when preparing SSPCMs based on these materials. Luyt and Brüll studied the extent of co-crystallisation of SSPCMs based on an oxidised wax (average $\mathrm{M}_{\mathrm{w}}=785 \mathrm{~g} \mathrm{~mol}^{-1}$, C/O ratio 18.8/1) with HDPE, LDPE and LLDPE [27]. The authors demonstrated extensive co-crystallisation of the wax with LLDPE, but little or no cocrystallisation with HDPE and LDPE.

However, there has been little research on the impact of different melting point waxes on the thermo-physical properties of the SSPCMs which are also prepared using a continuous, scalable and industrially relevant process such as twin-screw extrusion. In this paper, we describe the preparation of SSPCMs based on a high melt viscosity HDPE (hv-HDPE) with high $\left(\mathrm{H}-\mathrm{PW}, \mathrm{T}_{\mathrm{m}}=56-58^{\circ} \mathrm{C}\right)$ and low $\left(\mathrm{L}-\mathrm{PW}, \mathrm{T}_{\mathrm{m}}=18-23^{\circ} \mathrm{C}\right)$ melting point paraffin waxes using twin-screw extrusion at loadings up to $75 \%$ content by mass. The thermal and mechanical properties of all blends were determined. As the melting point of L-PW is close to the human comfort range, it could be used for heating and cooling in buildings [29]. Moreover, the higher $\mathrm{T}_{\mathrm{m}} \mathrm{H}-\mathrm{PW}$ could find application in solar water heating systems [22, 30]. 


\section{Experimental}

\subsection{Materials}

The hv-HDPE (Marlex ${ }^{\circledR}$ HHM TR-144 Polyethylene) used in this study was supplied by Qatar Chemical Company Ltd in pellet form, MFI = 0.18 g/10 min $\left(190{ }^{\circ} \mathrm{C} / 2.16 \mathrm{~kg}, \mathrm{ASTM}\right.$ D1238) and density $=0.946 \mathrm{~g} / \mathrm{cm}^{3}$. The H-PW was supplied in pellet form by TCS Biosciences Ltd, $\mathrm{T}_{\mathrm{m}}$ between $56-58{ }^{\circ} \mathrm{C}$. The hv-HDPE and H-PW were first ground to powder yielding a particle size smaller than $250 \mu \mathrm{m}$. The L-PW wax was supplied by Rubitherm Technologies $\mathrm{GmbH}$ and had a $\mathrm{T}_{\mathrm{m}}$ in the range of $18^{\circ} \mathrm{C}-23^{\circ} \mathrm{C}$.

\subsection{Sample preparation}

SSPCMs based on blends of hv-HDPE with H-PW loadings of 50, 65 and 75 wt\% and L-PW loadings of 40, 50 and 65 wt\% were prepared by twin-screw extrusion. All blends were compounded using a Dr Collin ZK25 twin-screw extruder, having an L/D of 30:1. For hvHDPE/H-PW blends, the pre-mixed hv-HDPE and H-PW were fed into a hopper and melt blended using a screw speed of $175 \mathrm{rpm}$. The temperature profile of the extruder was 120,150 , $170,170,170,170{ }^{\circ} \mathrm{C}$ from zone 1 (feeding zone) to the die end (zone 6), respectively. For hvHDPE/L-PW blends, the temperature profile of the extruder was 150, 165, 150, 160, 160, 160 ${ }^{\circ} \mathrm{C}$ from zone 1 to the die end (zone 6), respectively. hv-HDPE was fed into hopper and L-PW was fed into zone 2 via a peristaltic pump, as it is liquid at RT. The extruder screw speed was set at $300 \mathrm{rpm}$.

All extruded strands were cooled in a water bath and pelletized. The extruded pellets obtained were further compressed into $2 \mathrm{~mm}$ (for tensile test) and $4 \mathrm{~mm}$ (for flexural and compressive test) thick sheets in a Dr. Collin P200P platen press machine by utilising two rectangular moulds $(135 \times 135 \times 2 \mathrm{~mm}$ and $120 \times 120 \times 4 \mathrm{~mm})$ placed between the platens Compression moulding of all the samples included four steps. The sheets were pre-heated at $170{ }^{\circ} \mathrm{C}$ for 2 minutes between the platens followed by application of a forming pressure of 70 
bar for 5 minutes. The sheets were then cooled from $170{ }^{\circ} \mathrm{C}$ to $120^{\circ} \mathrm{C}$ in 2 minutes and from $120^{\circ} \mathrm{C}$ to $50^{\circ} \mathrm{C}$ in 3 minutes, and then allowed to cool to room temperature (RT) under ambient conditions.

\subsection{Characterisation}

Scanning Electron Microscopy (SEM) examination of all materials was carried using a JEOL 6500 JSM840A scanning electron microscope using an operating voltage of $3.0 \mathrm{kV}$. The specimens used were taken from $2 \mathrm{~mm}$ thick compression moulded samples. Fractured surfaces were obtained by fracturing samples in liquid nitrogen and then immersing them in xylene at room temperature to extract the paraffin wax component. This etched surface was investigated by SEM. Specimens were mounted on $25 \mathrm{~mm} \times 1 \mathrm{~mm}$ aluminium discs using Araldite rapid epoxy adhesive, allowed to cure for $24 \mathrm{~h}$ and subsequently sputtered with a $10 \mathrm{~nm}-20 \mathrm{~nm}$ thick coating of gold on the sample surface so as to impede charging effects and induce conductivity prior to SEM examination.

For Fourier Transform Infrared Spectroscopy (FTIR), thin microtomed sections (a few $\mu \mathrm{m}$ thick) were used for H-PW and all other blends. For L-PW, as it was in the liquid state at RT $\left(20 \pm 2^{\circ} \mathrm{C}\right)$, a small sample which covered the attenuated total reflectance (ATR) crystal was used. FTIR spectra were collected using a Perkin-Elmer Spectrum 1000 microspectrometer in the spectral range $600-4000 \mathrm{~cm}^{-1}$ at $\mathrm{RT}\left(20 \pm 2^{\circ} \mathrm{C}\right)$, with $4 \mathrm{~cm}^{-1}$ resolution and each spectrum averaged over 16 scans. The spectra of at least three specimens were collected for each sample.

X-Ray Diffraction (XRD) studies were carried out with a PANalytical X'Pert Pro Multipurpose Diffractometer using $\mathrm{Cu}-\mathrm{K}_{\alpha}$ radiation with a wavelength of $1.5406 \AA$, a scanning rate of $0.63{ }^{\circ} \mathrm{C} \min ^{-1}$ (step size of $0.02^{\circ}$ ) over a $2 \theta$ range of $1-60^{\circ} . \mathrm{X}^{\prime}$ Pert HighScore Plus Version 2.2 software was employed to analyse XRD data. 
Differential Scanning Calorimetry (DSC) analyses of H-PW and hv-HDPE/H-PW blends were completed using a Perkin Elmer DSC 6 instrument under flowing nitrogen (flow rate $20 \mathrm{~mL} \mathrm{~min}-1$ ). The instrument was calibrated using the onset temperatures of melting of indium standards, as well as the melting enthalpy of indium. Samples (5-10 mg) were sealed in aluminium pans and heated from $30^{\circ} \mathrm{C}$ to $160^{\circ} \mathrm{C}$ at a heating rate of $10 \mathrm{~K} \mathrm{~min}^{-1}$. In all cases, samples were held at $160{ }^{\circ} \mathrm{C}$ for $1 \mathrm{~min}$ and cooled to $30^{\circ} \mathrm{C}$ at $10 \mathrm{~K} \mathrm{~min}^{-1}$, then reheated again to $160{ }^{\circ} \mathrm{C}$ at $10 \mathrm{~K} \mathrm{~min}^{-1}$. DSC analysis of L-PW and hv-HDPE/L-PW blends was completed using a Perkin Elmer Diamond DSC under flowing nitrogen gas. Samples (5-10 mg) were sealed in aluminium pans and heated from $0{ }^{\circ} \mathrm{C}$ to $160{ }^{\circ} \mathrm{C}$ at a heating rate of $10 \mathrm{~K} \mathrm{~min}^{-1}$. In all cases, samples were held at $160{ }^{\circ} \mathrm{C}$ for $1 \mathrm{~min}$ and cooled to $0{ }^{\circ} \mathrm{C}$ at $10 \mathrm{~K} \mathrm{~min}^{-1}$ using liquid nitrogen as a coolant, and reheated again to $160{ }^{\circ} \mathrm{C}$ at $10 \mathrm{~K} \mathrm{~min}^{-1}$. Melting point $\left(\mathrm{T}_{\mathrm{m}}\right)$ and enthalpies of melting $\left(\Delta \mathrm{H}_{\mathrm{m}}\right)$ were determined from the second scan. All DSC measurements were repeated at least three times for each sample.

Thermo-gravimetric Analysis (TGA) was carried out in a TGA Analyser TGA/SDTA 851e/LF/1600/1382 (Mettler Toledo). Specimens ranging between $5 \mathrm{mg}$ and $10 \mathrm{mg}$ of each sample was loaded in aluminium pans and heated from $30{ }^{\circ} \mathrm{C}$ to $600{ }^{\circ} \mathrm{C}$ at a heating rate of 10 $\mathrm{K} \mathrm{min}^{-1}$ under flowing nitrogen (flow rate $50 \mathrm{ml} \mathrm{min}^{-1}$ ). The onset decomposition temperatures were determined from the weight loss curve by extrapolating the curve at $5 \mathrm{wt} \%$ weight loss for each blend.

Dynamic properties (storage modulus ( $\left.\mathrm{E}^{\prime}\right)$, loss modulus $\left(\mathrm{E}^{\prime \prime}\right)$ and tan $\delta$ ) of all samples with dimensions of $10 \mathrm{~mm} \times 10 \mathrm{~mm} \times 1 \mathrm{~mm}$ were measured using a Tritec 2000 dynamic mechanical thermal analysis (DMTA) instrument. The experiments were conducted in the temperature range $-100{ }^{\circ} \mathrm{C}$ to $100{ }^{\circ} \mathrm{C}$ using a heating rate of $2 \mathrm{~K} \mathrm{~min}^{-1}$ and a frequency of $1 \mathrm{~Hz}$. Tests were conducted in single cantilever bending mode at $0.05 \mathrm{~mm}$ controlled displacement. 
Tensile testing of hv-HDPE, hv-HDPE/H-PW and hv-HDPE/L-PW specimens was carried out using an Instron 5564 twin column tensile tester with a $5 \mathrm{kN}$ load cell along with a 2603-080 long travel extensometer using a 25 mm gauge length according to ISO 527-1:1996. A minimum of five dumbbell samples for each blend composition was loaded to the maximum strain of $1 \mathrm{~mm}$ or to failure at crosshead speeds of $5 \mathrm{~mm} \mathrm{~min}^{-1}$ and $50 \mathrm{~mm} \mathrm{~min}^{-1}$, respectively. The dumbbell samples had a total length of $75 \mathrm{~mm}$, a gauge length of $24 \mathrm{~mm}$, a neck width of $5 \mathrm{~mm}$, and a thickness of $2 \mathrm{~mm}$. The thickness and width of the samples were determined using a micro-meter prior to testing. All tensile properties (including Young's modulus, yield stress and elongation at break) were extracted from stress-strain curves using Merlin software (Version 5.51). Young's modulus was estimated from the slope of initial linear region of the stress-strain curves up to $2.5 \%$ strain. Analysis of variance (ANOVA) was used to test for significant differences among the mean of the tensile property of interest by quantifying the differences with the aid of Data Analysis ToolPak in Ms Excel, and the p-value was set to 5\%.

Flexural strength and modulus of hv-HDPE, hv-HDPE/H-PW and hv-HDPE/L-PW samples were measured in three-point bending tests using the same machine as that for tensile testing. Both flexural properties are of interest in the assessment of the blends as to whether they have sufficient mechanical strength for practical applications, e.g. in wallboards. The crosshead speed was $5 \mathrm{~mm} \mathrm{~min}^{-1}$ and specimens with dimensions of $80 \mathrm{~mm} \times 10 \mathrm{~mm} \times 4 \mathrm{~mm}$ (thickness) were cut from compression moulded plates of each blend by a band saw according to ISO 178. At least five specimens from each sample were tested.

Compression testing was performed on all specimens employing a strain rate of $5 \mathrm{~mm}$ $\min ^{-1}$ using an EZ 50 testing machine from Lloyd Instruments Ltd with a $5 \mathrm{kN}$ load cell. According to ISO 604, samples with dimensions of $10 \mathrm{~mm} \times 10 \mathrm{~mm} \times 4 \mathrm{~mm}$ were cut from the centre part of moulded plates of each blend. At least 6 specimens were tested for each blend composition and all tests were performed at ambient conditions of $20 \pm 2{ }^{\circ} \mathrm{C}$. 
The capillary rheological behaviour of hv-HDPE, hv-HDPE/H-PW and hv-HDPE/LPW samples in the shear rate range $50 \mathrm{~s}^{-1}$ to $1500 \mathrm{~s}^{-1}$ was investigated using a Bohlin Rosand RH2000 Capillary Rheometer with a 0.5 mm die and utilising the Rosand Flowmaster Precision Software. The rheological data obtained was Bagley corrected, to account for the non-linear pressure drop at the die entrance, thus correcting for wall shear stress and giving the true shear stress in capillary die [31, 32].

An oscillatory melt rheology study was carried out for hv-HDPE, hv-HDPE/H-PW and hv-HDPE/L-PW samples. Dynamic rheological measurements were performed using a HAAKE MARS rotational rheometer. The measurements were carried out in an oscillatory shear mode using parallel plate geometry (Standard Aluminium plate, $25 \mathrm{~mm}$ diameter, $1 \mathrm{~mm}$ gap) at $160{ }^{\circ} \mathrm{C}, 170{ }^{\circ} \mathrm{C}$ and $180^{\circ} \mathrm{C}$. Frequency sweeps from $1000 \mathrm{rad} / \mathrm{s}$ to $0.1 \mathrm{rad} / \mathrm{s}$ were carried out at low stress (2Pa) which was shown to be within the linear viscoelastic limit of all the materials used in this study.

\section{Results and discussion}

The surfaces of the hv-HDPE ${ }_{35} \mathrm{H}-\mathrm{PW}_{65}$ and hv-HDPE ${ }_{35} \mathrm{~L}-\mathrm{PW}_{65}$ blends are shown in Figure 1 (a) and (b), respectively (scale bar $1 \mu \mathrm{m}$ ). Both images indicate that hv-HDPE forms a 3D interconnected structure and the waxes are well dispersed within it. The hv-HDPE provides mechanical strength to the whole compound, and so the composite material keeps its shape in the solid state. Some voids on the surface of hv-HDPE 35 L-PW 65 (b), (indicated with arrows) were observed, perhaps as a consequence of air trapped during the manufacturing process or the expulsion of wax. The same two surfaces are shown in Figure 1 (c) and (d) but after treatment with xylene to extract the wax component. It can be seen that there are many voids in the etched surface of hv-HDPE ${ }_{35} \mathrm{H}-\mathrm{PW}_{65}$ (Fig. 1 (c)), indicative of where the H-PW resided in the hv-HDPE and again showing this wax to be well dispersed and distributed throughout 
the hv-HDPE matrix [20]. On the etched surface of hv-HDPE 35 L-PW 65 (Figure 1 (d)), the holes are less obvious than those observed in Figure 1 (c). This may be because the L-PW with smaller molecular size penetrated the hv-HDPE to a greater extent, including the crystalline lamellae, than H-PW. The fractured surfaces of the hv-HDPE ${ }_{35} \mathrm{H}-\mathrm{PW}_{65}$ and hv-HDPE $35 \mathrm{~L}-$ $\mathrm{PW}_{65}$ blends are shown in Figure 1 (e) and (f), respectively. More numerous voids and deformed structure were observed in Figure 1 (e). These were formed as the paraffin was pulled out when cryo-fracturing the sample, due to the limited wetting of the soft phase. In contrast, the voids observed in the hv-HDPE ${ }_{35} \mathrm{~L}_{-} \mathrm{PW}_{65}$ blend are less obvious and a less rough surface observed, Figure 1 (f).

As hv-HDPE and both waxes are non-polar, FTIR was used to confirm that blends of hv-HDPE with both waxes were physical mixes, see Figure 2 (a) and (b). The spectra obtained show four main characteristic IR bands at approximately $720 \mathrm{~cm}^{-1}, 1474 \mathrm{~cm}^{-1}, 2849 \mathrm{~cm}^{-1}$ and $2912 \mathrm{~cm}^{-1}$, which were assigned to $\mathrm{CH}_{2}$ rocking, $\mathrm{CH}_{2}$ bending, $\mathrm{CH}_{2}$ stretching and $\mathrm{CH}_{2}$ stretching, respectively [33]. There was no change of peak position and no new peaks generated for all samples, suggesting that there is no chemical interaction between the hvHDPE and waxes.

The crystalline content of H-PW, hv-HDPE and all blends was determined from the XRD diffractorgrams obtained at RT (Figure 3 (a) and (b)) for the hv-HDPE/H-PW and hvHDPE/L-PW blends), respectively. Two sharp reflection peaks at approximately $2 \theta=21.5^{\circ}$ and $23.8^{\circ}$ appear in the diffractograms for all composites, which can be assigned to the 110 and 200 basal planes of the orthorhombic crystal form of PE [33, 34]. Both peaks are more intense in the H-PW sample, indicating that it has higher crystalline content (93\%) and more regular structure than hv-HDPE (52\%). In all cases the crystalline content was determined from the ratio of crystalline to amorphous component in the blend with the aid of Jade 6.0 software [35, 36]. L-PW is liquid at RT and is thus non-crystalline. As the H-PW loading was increased 
from $50 \mathrm{wt} \%$ to $75 \mathrm{wt} \%$ when blended with hv-HDPE, the crystalline content of the blends increased up to $72 \%$, higher than that of pure hv-HDPE. In contrast, the crystalline content of the blends decreased to a low of 33\% with increasing L-PW content (up to $65 \mathrm{wt} \%$ ) and all values were lower than that of pure hv-HDPE itself. This may be associated with the penetration of the shorter chain L-PW into the HDPE lamellar structure during cooling, inhibiting hv-HDPE crystallisation.

The crystalline behaviour and thermal properties of these blends were also studied using DSC, see Figure 4. Melting peaks associated with both hv-HDPE and the respective waxes were identified in the DSC thermograms. $\mathrm{T}_{\mathrm{m}}$ of H-PW remained fairly constant, within experimental error, with increasing wax content for all blends. However, an increase in wax content resulted in a decrease in $\mathrm{T}_{\mathrm{m}}$ of hv-HDPE in hv-HDPE/H-PW blends. $\mathrm{T}_{\mathrm{m}}$ of L-PW increased slightly with increasing L-PW content in the blends, but again $\mathrm{T}_{\mathrm{m}}$ for hv-HDPE in the hv-HDPE/L-PW blends deceased with increasing hv-HDPE content. This we assume is a result of the plasticisation effect of both H-PW and L-PW on the hv-HDPE matrix as wax that crystallised separately melted before hv-HDPE, and this molten wax acted as a plasticiser [2325]. However, the wax that co-crystallised with hv-HDPE chains melted at the same temperature as the hv-HDPE, and therefore did not contribute to the plasticising effect of the wax.

As shown in Table 1 , the experimentally observed melting enthalpies $\left(\Delta \mathrm{H}_{\mathrm{m}}\right)$ of $\mathrm{H}-\mathrm{PW}$ are lower than the calculated enthalpies $\left(\Delta \mathrm{H}_{\mathrm{m} \delta}\right)$. The $\Delta \mathrm{H}_{\mathrm{m} \delta}$ values were determined from the melting enthalpy of the unblended pure H-PW compensating for the fraction of H-PW in the hv-HDPE/H-PW blends. The difference between the two enthalpies became insignificant with increasing wax content, indicating that some portion of H-PW partially co-crystallised with hvHDPE. The difference between the observed and the calculated enthalpies was for the hvHDPE/L-PW blends as shown in Table 2, as there was little or no co-crystallisation between 
hv-HDPE and L-PW [25]. The cooling curves of all samples can be seen in Figure 4 (b) and (d). The solidification point of H-PW in hv-HDPE/H-PW blends was almost constant while the crystallisation point of L-PW in hv-HDPE/L-PW blends shifted to lower temperatures. The solidification point of hv-HDPE in hv-HDPE/H-PW blends shifted to lower temperatures with increasing wax content, while the solidification point of hv-HDPE in hv-HDPE/L-PW blends remained almost constant. Again, there is less co-crystallisation of hv-HDPE with L-PW relative to that with $\mathrm{H}-\mathrm{PW}[24,25]$. The enthalpy of fusion $\left(\Delta \mathrm{H}_{\mathrm{c}}\right)$ of $\mathrm{H}-\mathrm{PW}$ in hv-HDPE/HPW blends was lower than the theoretical values expected, clearly obvious for the 50:50 blend, see Table 3, again as a consequence of co-crystallisation of hv-HDPE and H-PW [25]. $\Delta \mathrm{H}_{\mathrm{c}}$ for L-PW in hv-HDPE/L-PW blends were lower than the theoretical values expected (Table 4). In this instance, there may be a contribution associated with evaporation of some L-PW during the heating cycles in the DSC instrument.

TGA and DTG curves for H-PW, hv-HDPE and all hv-HDPE/H-PW blends are shown in Figure 5 (a) and (b), while those for L-PW, hv-HDPE and hv-HDPE/L-PW blends are shown in Figure 5 (c) and (d), respectively. For all the blends thermal stability decreased with increasing wax content, as the waxes have much shorter chains and more thermally labile than pure hv-HDPE [37]. Both hv-HDPE/H-PW and hv-HDPE/L-PW blends degraded via two clearly distinguishable steps. Such degradation behaviour is typical for immiscible blends in which the components have different degradation temperatures [18]. For all the blends the percentage mass loss during the first degradation step correlated well with the amount of wax initially added to the blend. The second step was associated with hv-HDPE degradation [38]. The degradation products are mainly hydrocarbon compounds, e.g. alkanes (methane, ethane and propane), alkenes (ethylene and propylene) and di-alkenes (butadiene) [39, 40]. It can be seen from the DTG curves (Figure 5 (b)) that when the temperature reached about $220{ }^{\circ} \mathrm{C}, \mathrm{H}$ PW started to decompose or evaporate until none remained at $440{ }^{\circ} \mathrm{C}$. In the second period 
when the temperature reached $450{ }^{\circ} \mathrm{C}$, hv-HDPE started to decompose and was fully decomposed at $510{ }^{\circ} \mathrm{C}$ leaving no residues. From Figure 5 (d), L-PW started to decompose at around $130{ }^{\circ} \mathrm{C}$, peaked at about $190{ }^{\circ} \mathrm{C}$, but none remained at $250{ }^{\circ} \mathrm{C}$. The decomposition behaviour of hv-HDPE was again similar to that shown in Figure 5 (b), as expected. Thus, we propose that mixing paraffin waxes with molten HDPE using twin screw extrusion is readily feasible as long as the wax of interest is thermally stable at the melt processing temperatures, in this instance of HDPE $\left(\sim 160{ }^{\circ} \mathrm{C}\right)$.

The results of the dynamic mechanical thermal analysis (DMTA) of all the investigated samples are shown in Figure 6. Plots of $\tan \delta$ versus temperature, Figure 6 (a) and (b), show that the hv-HDPE/H-PW blends had two relaxation maxima, one centred at around $-60{ }^{\circ} \mathrm{C}$, the other at about $56{ }^{\circ} \mathrm{C}$. The first relaxation peak around $-60{ }^{\circ} \mathrm{C}$ could be assigned to the glass transition of H-PW [44]. In contrast, for unfilled hv-HDPE no obvious peak in $\tan \delta$ was obtained in the temperature range examined. The latter peak around $56{ }^{\circ} \mathrm{C}$ could be attributed to a solid-liquid transition in H-PW [45]. Similar behaviour was observed for the hv-HDPE/LPW blends, which can be explained in a similar manner. As expected, the storage modulus E', as function of temperature, decreased with increasing wax content for all blends (Figure 6 (c) and (d)), again evidence for plasticising of hv-HDPE by the wax component. Also, there are large differences in mechanical properties due to the different structures and molar masses between wax and hv-HDPE [41]. As can be seen from Figure 6 (c), E' instead of an immediate decrease, decreased gradually after H-PW had completely melted in the high temperature region, similarly for all the blends, indicating that hv-HDPE forms a continuous phase in all the blends even at high wax content $[41,42]$. A similar conclusion can be made for the hvHDPE/L-PW blends.

Plots of loss modulus ( $E^{\prime \prime}$ ) versus temperature, see Figure 6 (e) and (f), show that pure hv-HDPE has two relaxation maxima, one centred at around $-25{ }^{\circ} \mathrm{C}$ and the other at about 45 
${ }^{\circ} \mathrm{C}$. The first maximum is derived from the glass transition $\left(\mathrm{T}_{\mathrm{g}}\right)$ of the hv-HDPE phase, although this continues to be a matter of fundamental scientific discussion. The latter peak is the $\alpha$ relaxation, related to the onset of molecular motion in the crystalline phase [43]. However, the two peaks shifted to lower temperatures for the hv-HDPE/H-PW blends, to about $-60{ }^{\circ} \mathrm{C}$ and $30^{\circ} \mathrm{C}$, respectively. Again, this is strong evidence for a plasticisation effect by the wax component on the hv-HDPE matrix [41]. From Figure 6 (f), the two relaxation peaks in the hvHDPE/L-PW blends decreased significantly, almost disappearing, as the wax content was increased. The material is becoming more viscous/less elastic due to a reduction in chain dynamics (relaxation) of the hv-HDPE phase [41].

Static tensile testing was performed at room temperature (RT) on hv-HDPE, hvHDPE/H-PW and hv-HDPE/L-PW blends. The Young's moduli (E) of both hv-HDPE/H-PW and hv-HDPE/L-PW blends were lower than that of pure hv-HDPE (see Figure 7 (a)). In both instances, E decreased with increasing wax content up to about $40 \mathrm{wt} \%$, from 700MPa for unfilled hv-HDPE down to 410MPa and 160MPa for H-PW and L-PW addition, respectively. The difference in the increment between the moduli of both sets of blends is associated with the higher relative crystallinity of H-PW. Further successive additions of either wax did not result in a statistically significant change in E, as assessed by ANOVA analysis. The yield stress of hv-HDPE/H-PW blends (see Figure 7 (b)) decreased with increasing H-PW content, which is as expected as the H-PW is weaker than hv-HDPE [46]. However, the yield stress of hv-HDPE/L-PW blends decreased first, up to $50 \mathrm{wt} \%$, but then formed a plateau when increasing the L-PW content to $65 \mathrm{wt} \%$. It can be seen that yield stress of the hv-HDPE/H-PW blends was much higher than that of hv-HDPE/L-PW blends, as L-PW is weaker and softer than H-PW, so when added to hv-HDPE the resulting blends are more easily deformed. This is also related to the lower crystalline content of the blends with L-PW, see Table 1 . The change in strain at break for hv-HDPE, hv-HDPE/H-PW and hv-HDPE/L-PW blends is shown in 
Figure 7 (c), and as expected the strain at break for the hv-HDPE/H-PW blends is much lower than that of hv-HDPE/L-PW blends. This behaviour can be further explained by examining the stress-strain curves for these blends, see Figure 8. Strain-hardening before break was observed for pure hv-HDPE sample, while no strain-hardening was observed for the hv-HDPE/H-PW blends (Figure 8 (a)). The strain at break of hv-HDPE is much higher than that of hv-HDPE/HPW blends. This is because the polymer chains have the free volume and time to orientate when the tensile force is applied. When the chains are oriented, they start to align and crystallise (strain induced crystallisation), which gives rise to an increase in both strength and strain at break [47]. However, adding H-PW in such large loadings to the polymer matrix reduces polymer chain mobility (hinders dynamics), resulting in a rapid decrease in strain at break. An increase in H-PW content resulted in a decrease in strain at break for all hv-HDPE/H-PW blends (Figure 8 (a)). This can also be explained by the more crystalline and numerous H-PW crystals acting as defect points for the initiation and propagation of stress cracking [48]. Strainhardening before break was observed for all hv-HDPE/L-PW samples, see Figure 8 (b). Strain at break for the hv-HDPE/L-PW blends is much larger than that for the hv-HDPE/H-PW blends, as the smaller non-crystalline L-PW molecules penetrated the hv-HDPE matrix and did not act as a barrier to stretching/deformation. Moreover, the strain at break of all hv-HDPE/LPW blends decreased with increasing L-PW content, probably because the average tie chain concentration in the composites decreased with increasing L-PW content (reduced hv-HDPE content) [48].

The changes in flexural modulus and stress of the hv-HDPE/H-PW and hv-HDPE/LPW blends as a function of wax content are shown in Figure 9 (a) and (b), respectively. Both properties for the hv-HDPE/H-PW blends are much higher than those of the hv-HDPE/L-PW blends. We suppose that as the L-PW is weaker than H-PW and in the molten state at RT, it cannot provide limited mechanical strength when under flexural stress. The flexural modulus 
and stress decreased with increasing wax content in all blends, not unexpected as the waxes are much weaker than neat hv-HDPE (see Figure 9 (c) and (d)). It is worth noting that this is an important consideration should such materials find civil engineering application(s). The change in compression moduli with wax content for all samples is shown in Figure 10 (a), and the stress-strain data from compression testing of hv-HDPE/H-PW and hv-HDPE/L-PW blends is Figure 10 (b) and (c), respectively. The compression modulus of hv-HDPE/H-PW blends is higher than that of hv-HDPE/L-PW blends. As the crystalline content for the hv-HDPE/L-PW blends is much lower than that of hv-HDPE/H-PW blends, it was expected that the compression modulus should also be lower for the blends with L-PW added. The compression modulus decreases with increasing wax content for all blends as the waxes are much softer mechanically compared to pure hv-HDPE, but to a great extent for the blends with L-PW addition.

As a further consideration if such SSPC materials are to be readily manufactured using polymer processing methods, such as with twin screw extrusion, the melt rheological behaviour of these blends must be understood at high shear rates. To this end, the effect of shear rate on shear viscosity of pure hv-HDPE, hv-HDPE/H-PW and hv-HDPE/L-PW blends was investigated by dual capillary rheology at $160{ }^{\circ} \mathrm{C}, 170{ }^{\circ} \mathrm{C}$ and $180{ }^{\circ} \mathrm{C}$ in the shear rate range $50 \mathrm{~s}^{-1}-1500 \mathrm{~s}^{-1}$. This shear rate range covers the shear typically employed during polymer extrusion. The data obtained from rheological measurements were Bagley corrected in order to obtain true shear stress values by taking into account the pressure drop at the entrance of the die, along its length and at its exit [31, 32, 49]. By way of example, Figure 11 (a) and (b) show the results obtained at $160{ }^{\circ} \mathrm{C}$ for both sets of blends. It is as expected, that by increasing screw speed, the shear stress and the energy added to the system increased and consequently the shear viscosity decreased making the system more favourable for wax dispersion and distribution in the hv-HDPE matrix. Furthermore, for a similar wax addition the melt viscosity of the blends with L-PW were lower than those with H-PW - in the shear rate range examined $\left(50 \mathrm{~s}^{-1}\right.$ - 1500 
$\mathrm{s}^{-1}$ ). Similar behaviour was found for the measurements at $170{ }^{\circ} \mathrm{C}$ and $180{ }^{\circ} \mathrm{C}$. The lower viscosity of the blends would imply that it could be more easily melt processed an important consideration in the manufacturing step, if for example sheets of such materials were to be used in construction applications. This is associated with the lower viscosity of molten wax compared with that of hv-HDPE. By increasing the temperature, the total energy added to the system during the mixing process increases and consequently the shear viscosity is expected to decrease. However, as it can be seen from Figure 11 (c), the difference between the shear viscosity of hv-HDPE ${ }_{50} \mathrm{H}-\mathrm{PW}_{50}$ measured at $160{ }^{\circ} \mathrm{C}, 170{ }^{\circ} \mathrm{C}$ and $180{ }^{\circ} \mathrm{C}$ cannot be regarded as significant. Similar results were found for hv-HDPE ${ }_{50} \mathrm{~L}_{-} \mathrm{PW}_{50}$, Figure 11 (d). This might be explained by that as each blend is consisted of a considerable large proportion of wax with a melting point far below $160{ }^{\circ} \mathrm{C}$, the effect of increment of temperature from $160{ }^{\circ} \mathrm{C}$ to $170{ }^{\circ} \mathrm{C}$ or from $170{ }^{\circ} \mathrm{C}$ to $180^{\circ} \mathrm{C}$ on the shear viscosity for the blends is not significant. Thus, $160{ }^{\circ} \mathrm{C}$ is an adequate processing temperature. This is an important consideration as the lower the temperature, the less energy required to mix the blend components, but also less evaporation of wax, especially for hv-HDPE/L-PW blends.

To further investigate the interaction between and dispersion of wax in hv-HDPE, an oscillatory melt rheology study, at low shear rates, was also carried out. Polymers exhibit viscoelastic behaviour which is directly related to molecular structure. In order to evaluate the relationship between molecular structure and viscoelastic behaviour it is necessary to perform rheological experiments in the linear viscoelastic region where the viscoelastic properties observed are independent of imposed stress or strain level. An oscillatory stress sweep test was performed to establish the linear viscoelastic region and determine the maximum stress for linear behaviour at $160{ }^{\circ} \mathrm{C}$. The limit of the viscoelastic regime for each material is determined by the stress value when the moduli ( $G^{\prime}$ and $\left.G^{\prime \prime}\right)$ start to decrease becoming non-linear. In this study, a stress value of $2 \mathrm{~Pa}$ was selected as all the samples were in linear viscoelastic region at 
this value. As shown in Figure 12 (a) and (b), with increasing frequency, the storage modulus G' increased for all samples, approximately by two orders of magnitude. G' of hv-HDPE is higher than the two sets of the blends. With increasing wax content, G' decreased. This is associated with the less viscous property of the waxes at elevated temperatures. However, the plots of hv-HDPE ${ }_{35} \mathrm{H}-\mathrm{PW}_{65}$ and hv-HDPE $25 \mathrm{H}-\mathrm{PW}_{75}$ were nearly overlapping, and lie below that for hv-HDPE ${ }_{50} \mathrm{H}-\mathrm{PW}_{50}$, see Figure 12 (a). G' of the three hv-HDPE/L-PW composites were very similar in the low frequency region and separated at high frequencies, as shown in Figure 12 (b). Plots of log shear viscosity $\eta^{\prime}$ vs $\log$ frequency f are shown in Figure 12 (c) and (d). With increase $f, \eta$ ' decreased in all samples. This is because when shear rate increased, the entanglement of the molecular of hv-HDPE decreased. With increasing wax content, the viscosity of all composites decreased, again associated with the less viscous properties of the waxes. However, the difference between the viscosity values of hv-HDPE ${ }_{35} \mathrm{H}-\mathrm{PW}_{65}$ and hv$\mathrm{HDPE}_{25} \mathrm{H}-\mathrm{PW} 75$ is not significant. A Cole-Cole plot (Log G' versus log G" plot) is a sensitive tool that can probe composite miscibility/compatibility in that changing slopes of the linear relationship between both parameters can indicate poor interaction, in this instance between hv-HDPE and wax. Curves corresponding to different wax content deviate slightly from each other and from pure hv-HDPE, Figure 12 (e) and (f), and indicated less interaction between hvHDPE and wax at higher wax loading, evidence for induced heterogeneity within the composite material $[50,51]$.

\section{Conclusions}

Both H-PW and L-PW could be mixed uniformly with hv-HDPE to form SSPCMs using twin screw extrusion, and the blends formed are physical mixes with no evidence of chemical interaction between blend components. The extrusion temperature for hv-HDPE/LPW blends should not be $>160{ }^{\circ} \mathrm{C}$, as the onset of the evaporation temperature of $\mathrm{L}-\mathrm{PW}$ is 
relatively low, $\leq 130{ }^{\circ} \mathrm{C}$. However, the extent of L-PW evaporation we assume is low as the residence time of L-PW in the extruder is less than 30 sec. No such consideration is required for blends prepared with H-PW. The SSPCMs had latent heats up to $89 \mathrm{~J} / \mathrm{g}$ (hv-HDPE ${ }_{25} \mathrm{H}-$ PW 75 ), as determined from DSC analysis and thus these composite materials are candidates for LHTES applications. The enthalpy of H-PW in SSPCM blends decreased while that of L-PW remained unaltered, as a consequence of co-crystallisation between H-PW and hv-HDPE. DMTA analyses show the plasticising effect of both waxes on the hv-HDPE matrix. The mechanical properties, moduli and stress, irrespective of mode of deformation are much greater for the hv-HDPE/H-PW blends compared with those of the hv-HDPE/L-PW blends at RT. The tensile and flexural strength of hv-HDPE/H-PW blends were much greater than hv-HDPE/LPW blends at RT. The rheological behaviour of these blends confirmed increased heterogeneity with increasing wax content and that melt processing such SSPCMs with conventional polymer processing techniques should be routine, at least for the wax loadings used in this study. Further studies are ongoing to address some of the many limitations of such SSPCMs [52], e.g. thermal conductivity, and will be reported shortly.

\section{Acknowledgements}

MM thanks the UK-China Sciences Bridge Project for financial support, and we acknowledge Mr Graham Garrett and Dr Bronagh Miller for technical assistance. 


\section{References}

1. Khudhair, A.M. and M.M. Farid, A review on energy conservation in building applications with thermal storage by latent heat using phase change materials. Energy conversion and management, 2004. 45(2): p. 263-275.

2. Tyagi, V.V. and D. Buddhi, PCM thermal storage in buildings: A state of art. Renewable and Sustainable Energy Reviews, 2007. 11(6): p. 1146-1166.

3. Zhang, Y., et al., Application of latent heat thermal energy storage in buildings: State-of-the-art and outlook. Building and Environment, 2007. 42(6): p. 2197-2209.

4. $\quad$ Pasupathy, A., R. Velraj, and R. Seeniraj, Phase change material-based building architecture for thermal management in residential and commercial establishments. Renewable and Sustainable Energy Reviews, 2008. 12(1): p. 39-64.

5. Raj, V. and R. Velraj, Review on free cooling of buildings using phase change materials. Renewable and Sustainable Energy Reviews, 2010. 14(9): p. 2819-2829.

6. Arkar, C. and S. Medved, Free cooling of a building using PCM heat storage integrated into the ventilation system. Solar energy, 2007. 81(9): p. 1078-1087.

7. Zhou, G., et al., Thermal analysis of a direct-gain room with shape-stabilized PCM plates. Renewable Energy, 2008. 33(6): p. 1228-1236.

8. Hadjieva, M., R. Stoykov, and T. Filipova, Composite salt-hydrate concrete system for building energy storage. Renewable Energy, 2000. 19(1): p. 111-115.

9. Inaba, H. and P. Tu, Evaluation of thermophysical characteristics on shape-stabilized paraffin as a solid-liquid phase change material. Heat and Mass Transfer, 1997. 32(4): p. 307-312.

10. Wang, L.J. and D. Meng, Fatty acid eutectic/polymethyl methacrylate composite as form-stable phase change material for thermal energy storage. Applied Energy, 2010. 87(8): p. 2660-2665.

11. Wang, W.L., et al., Preparation and performance of form-stable polyethylene glycol/silicon dioxide composites as solid-liquid phase change materials. Applied Energy, 2009. 86(2): p. 170-174.

12. Sharma, A., et al., Review on thermal energy storage with phase change materials and applications. Renewable and Sustainable Energy Reviews, 2009. 13(2): p. 318345.

13. Himran, S., A. Suwono, and G.A. Mansoori, Characterization of alkanes and paraffin waxes for application as phase change energy storage medium. Energy Sources, 1994. 16(1): p. 117-128.

14. Hong, Y. and X.S. Ge, Preparation of polyethylene-paraffin compound as a formstable solid-liquid phase change material. Solar Energy Materials and Solar Cells, 2000. 64(1): p. 37-44.

15. Cai, Y., et al., Preparation and characterizations of HDPE-EVA alloy/OMT nanocomposites/paraffin compounds as a shape stabilized phase change thermal energy storage material. Thermochimica acta, 2006. 451(1): p. 44-51.

16. Molefi, J., A. Luyt, and I. Krupa, Comparison of LDPE, LLDPE and HDPE as matrices for phase change materials based on a soft Fischer-Tropsch paraffin wax. Thermochimica Acta, 2010.500(1): p. 88-92.

17. Xiao, M., B. Feng, and K. Gong, Preparation and performance of shape stabilized phase change thermal storage materials with high thermal conductivity. Energy Conversion and Management, 2002. 43(1): p. 103-108.

18. Zhang, P., et al., The influence of expanded graphite on thermal properties for paraffin/high density polyethylene/chlorinated paraffin/antimony trioxide as a flame 
retardant phase change material. Energy Conversion and Management, 2010. 51(12): p. 2733-2737.

19. Alkan, C., K. Kaya, and A. Sar1, Preparation, thermal properties and thermal reliability of form-stable paraffin/polypropylene composite for thermal energy storage. Journal of Polymers and the Environment, 2009. 17(4): p. 254-258.

20. Lee, C.H. and H.K. Choi, Crystalline morphology in high density polyethylene/paraffin blend for thermal energy storage. Polymer Composites, 1998. 19(6): p. 704-708.

21. Zhang, Y., et al., Preparation, thermal performance and application of shapestabilized PCM in energy efficient buildings. Energy and Buildings, 2006. 38(10): p. 1262-1269.

22. Sari, A., Form-stable paraffin/high density polyethylene composites as solid-liquid phase change material for thermal energy storage: preparation and thermal properties. Energy Conversion and Management, 2004. 45(13-14): p. 2033-2042.

23. Kaygusuz, K. and A. Sari, High density polyethylene/paraffin composites as formstable phase change material for thermal energy storage. Energy Sources Part aRecovery Utilization and Environmental Effects, 2007. 29(3): p. 261-270.

24. Hato, M.J. and A. Luyt, Thermal Fractionation and Properties of Different Polyethylene/Wax Blends. Journal of Applied Polymer Science, 2007. 104(4): p. 2225-2236.

25. Mngomezulu, M., A. Luyt, and I. Krupa, Structure and properties of phase change materials based on HDPE, soft Fischer-Tropsch paraffin wax, and wood flour. Journal of Applied Polymer Science, 2010. 118(3): p. 1541-1551.

26. Mngomezulu, M., A. Luyt, and I. Krupa, Structure and properties of phase-change materials based on high-density polyethylene, hard Fischer-Tropsch paraffin wax, and wood flour. Polymer Composites, 2011. 32(8): p. 1155-1163.

27. Luyt, A. and R. Brüll, Investigation of polyethylene-wax blends by CRYSTAF and SEC-FTIR. Polymer Bulletin, 2004. 52(2): p. 177-183.

28. Yan, Q., L. Li, and D. Shen, Thermal properties of shape-stabilized paraffin used for wallboard. International Journal of Sustainable Energy, 2010. 29(2): p. 87-95.

29. Kuznik, F., et al., A review on phase change materials integrated in building walls. Renewable and Sustainable Energy Reviews, 2011. 15(1): p. 379-391.

30. Xiao, M., B. Feng, and K.C. Gong, Thermal performance of a high conductive shapestabilized thermal storage material. Solar Energy Materials and Solar Cells, 2001. 69(3): p. 293-296.

31. Bagley, E., End corrections in the capillary flow of polyethylene. Journal of Applied Physics, 1957. 28(5): p. 624-627.

32. Sombatsompop, N. and N.-T. Intawong, Flow properties and entrance corrections of polymer melts by a mobile barrel capillary rheometer. Polymer testing, 2000. 20(1): p. 97-103.

33. Vakhshouri, A.R., et al., Preparation and study of thermal properties of phase change materials based on paraffin-alumina-filled polyethylene. Journal of applied polymer science, 2011. 120(4): p. 1907-1915.

34. Wang, J., S.J. Severtson, and A. Stein, Significant and concurrent enhancement of stiffness, strength, and toughness for paraffin wax through organoclay addition. Advanced Materials, 2006. 18(12): p. 1585-1588.

35. Lin Yang, J.C., Huilin Li, Investigation on the microstructure and electric property of poly(propylene)/chlorinated poly(propylene)/poly(aniline) composites. Journal of Applied Polymer Science, 2009. 111(2): p. 988-997. 
36. Guang Lu Han, Y.G., Qiu Gen Zhang, Qing Lin Liu, Polyarylethersulfone with cardo/poly (vinyl pyrrolidone) blend membrane for pervaporation of methanol/methyl tert-buty ether mixtures. Journal of Membrane Science, 2013. 448: p. 55-61.

37. Cai, Y.B., et al., Flammability and thermal properties of high density polyethylene/paraffin hybrid as a form-stable phase change material. Journal of Applied Polymer Science, 2006. 99(4): p. 1320-1327.

38. Sittisart, P. and M.M. Farid, Fire retardants for phase change materials. Applied Energy, 2011. 88(9): p. 3140-3145.

39. Tsuchiya, Y. and K. Sumi, Thermal decomposition products of polyethylene. Journal of Polymer Science Part A 1: Polymer Chemistry, 1968. 6(2): p. 415-424.

40. Mastral, F., et al., Fluidized bed thermal degradation products of HDPE in an inert atmosphere and in air-nitrogen mixtures. Journal of Analytical and Applied Pyrolysis, 2003. 70(1): p. 1-17.

41. Krupa, I., G. Miková, and A. Luyt, Phase change materials based on low-density polyethylene/paraffin wax blends. European Polymer Journal, 2007. 43(11): p. 46954705.

42. Krupa, I., G. Miková, and A. Luyt, Polypropylene as a potential matrix for the creation of shape stabilized phase change materials. European polymer journal, 2007. 43(3): p. 895-907.

43. Shieh, Y.T., H.C. Chuang, and C.M. Liu, Water crosslinking reactions of silanegrafted polyolefin blends. Journal of Applied Polymer Science, 2001. 81(7): p. 17991807.

44. Mngomezulu, M.E., Phase Change Materials Based on Polyethylene, Paraffin Wax and Wood Flour, 2009, University of the Free State (Qwaqwa Campus).

45. Mochane, M.J., Polymer Encapsulated Paraffin Wax to be Used as Phase Change Material for Energy Storage, 2011, University of the Free State (Qwaqwa Campus).

46. Molefi, J.A., A.S. Luyt, and I. Krupa, Comparison of LDPE, LLDPE and HDPE as matrices for phase change materials based on a soft Fischer-Tropsch paraffin wax. Thermochimica Acta, 2010. 500(1-2): p. 88-92.

47. Haward, R., Strain hardening of thermoplastics. Macromolecules, 1993. 26(22): p. 5860-5869.

48. Hlangothi, S., et al., Thermal and mechanical properties of cross-linked and uncrosslinked linear low-density polyethylene-wax blends. Polymer Degradation and Stability, 2003. 79(1): p. 53-59.

49. Macosko, C., Rheology: Principles, Measurements, and Applications; VCH: New York, 1994.

50. Nandi, S., et al., Dynamic rheology and morphology of HDPE-fumed silica composites: Effect of interface modification. Polymer Engineering \& Science, 2012. 55(3): p. 644-650.

51. Han, C.D. and Chuang H.K., Criteria for rheological compatibility of polymer blends. Journal of Applied Polymer Science, 1985. 30(11): p. 4431-4454.

52. Pielichowska, K. and Pielichowski, K., Phase change materials for thermal storage. Progress in Materials Science, 2014.65: p. 67-123. 


\section{Table and Figure Captions}

Table 1 Thermal properties of hv-HDPE/H-PW blends (melting) as determined from DSC measurements.

Table 2 Thermal properties of hv-HDPE/L-PW blends (melting) as determined from DSC measurements.

Table 3 Thermal properties of hv-HDPE/H-PW blends (crystallisation) as determined from DSC measurements.

Table 4 Thermal properties of hv-HDPE/L-PW blends (crystallisation) as determined from DSC measurements.

Figure 1 SEM images of (a) surface of hv-HDPE ${ }_{35} \mathrm{H}_{-} \mathrm{PW}_{65}$; (b) surface of hv-HDPE ${ }_{35} \mathrm{H}-$ $\mathrm{LW}_{65}$; (c) surface of hv-HDPE ${ }_{35} \mathrm{H}-\mathrm{PW}_{65}$ after xylene treatment; (d) surface of hv-HDPE ${ }_{35} \mathrm{H}-$ $\mathrm{PW}_{65}$ after xylene treatment; (e) fractured surface of hv-HDPE ${ }_{35} \mathrm{H}-\mathrm{PW} 65$ and (f) fractured surface of hv-HDPE ${ }_{35} \mathrm{H}-\mathrm{PW}_{65}$.

Figure 2 FTIR spectra of (a) H-PW, hv-HDPE and hv-HDPE/H-PW blends, and (b) L-PW, hv-HDPE and hv-HDPE/L-PW blends.

Figure 3 XRD diffractograms of (a) H-PW, hv-HDPE and hv-HDPE/H-PW blends, and (b) hv-HDPE and hv-HDPE/L-PW blends.

Figure 4 DSC thermograms for (a) heating curves of H-PW, hv-HDPE and hv-HDPE/H-PW blends; (b) cooling curves of H-PW, hv-HDPE and hv-HDPE/H-PW blends; (c) heating curves of L-PW, hv-HDPE and hv-HDPE/L-PW blends and (d) cooling curves of L-PW, hv-HDPE and hv-HDPE/L-PW blends. 
Figure 5 TGA curves for (a) H-PW, hv-HDPE and hv-HDPE/H-PW blends; DTG curves for (b) H-PW, hv-HDPE and hv-HDPE/H-PW blends; TGA curves for (c) L-PW, hv-HDPE and hv-HDPE/L-PW blends and DTG curves for (d) L-PW, hv-HDPE and hv-HDPE/L-PW blends.

Figure 6 DMTA results of (a) Tan $\delta$ of hv-HDPE and hv-HDPE/H-PW blends; (b) Tan $\delta$ of hv-HDPE and hv-HDPE/L-PW blends; (c) storage modulus (E') for hv-HDPE and hvHDPE/H-PW blends; (d) E' for hv-HDPE and hv-HDPE/L-PW blends; (e) loss modulus (E") of hv-HDPE and hv-HDPE/H-PW blends; (f) E" of hv-HDPE and hv-HDPE/L-PW blends, as a function of temperature.

Figure 7 Tensile testing results of variation in (a) Young's modulus, (b) yield stress and (c) strain at break of hv-HDPE, hv-HDPE/H-PW and hv-HDPE/L-PW blends, as a function of wax content.

Figure 8 Stress-strain curves of (a) hv-HDPE and hv-HDPE/H-PW blends and (b) hv-HDPE and hv-HDPE/L-PW blends.

Figure 9 Flexural testing results of variation in (a) flexural modulus and (b) flexural stress of hv-HDPE, hv-HDPE/H-PW and hv-HDPE/L-PW blends, as a function of wax content; stressstrain curves for (c) hv-HDPE and hv-HDPE/H-PW blends and (d) hv-HDPE and hv-HDPE/LPW blends.

Figure 10 Compression testing results of (a) variation in compression modulus of hv-HDPE, hv-HDPE/H-PW and hv-HDPE/L-PW blends, as a function of wax content; stress-strain curves for (a) hv-HDPE and hv-HDPE/H-PW blends and (b) hv-HDPE and hv-HDPE/L-PW blends.

Figure 11 Capillary rheology: plots of log shear viscosity versus log shear rate for (a) hvHDPE and hv-HDPE/H-PW and (b) hv-HDPE and hv-HDPE/L-PW blends at $160{ }^{\circ} \mathrm{C}$; plots of 
log shear viscosity versus log shear rate for (c) hv-HDPE50H-PW50 and (d) hv-HDPE50LPW50 blends at three different temperatures.

Figure 12 Oscillatory rheology: plots of log G' versus log $\mathrm{f}$ for (a) hv-HDPE and hv-HDPE/HPW blends and (b) hv-HDPE and hv-HDPE/L-PW blends; plots of log $\eta^{\prime}$ versus log $\mathrm{f}$ plot of (c) hv-HDPE and hv-HDPE/H-PW blends and (d) hv-HDPE and hv-HDPE/L-PW blends; plots of log G' versus log G" (Cole-Cole plots) for (e) hv-HDPE and hv-HDPE/H-PW blends and (f) hv-HDPE and hv-HDPE/L-PW blends, at $160^{\circ} \mathrm{C}$. 
Table 1

\begin{tabular}{|c|c|c|c|c|c|c|c|c|}
\hline $\begin{array}{c}\text { hv-HDPE/ } \\
\text { H-PW }\end{array}$ & $\begin{array}{c}T_{m} \text { peak } \\
\left({ }^{\circ} \mathrm{C}\right) \\
\end{array}$ & $\begin{array}{c}\Delta \mathrm{H}_{\mathrm{m}} \\
\left(\mathrm{J} \mathrm{g}^{-1}\right) \\
\end{array}$ & $\begin{array}{l}\Delta \mathrm{H}_{\mathrm{m} \delta} \\
\left(\mathrm{J} \mathrm{g}^{-1}\right)\end{array}$ & $\begin{array}{c}\mathrm{T}^{\prime} \mathrm{m} \text { onset } \\
\left({ }^{\circ} \mathrm{C}\right)\end{array}$ & $\begin{array}{c}T^{\prime} \text { m peak } \\
\left({ }^{\circ} \mathrm{C}\right) \\
\end{array}$ & $\begin{array}{l}\Delta \mathrm{H}^{\prime} \mathrm{m} \\
\left(\mathrm{J} \mathrm{g}^{-1}\right)\end{array}$ & $\begin{array}{l}\Delta \mathrm{H}^{\prime} \mathrm{m} \delta \\
\left(\mathrm{J} \mathrm{g}^{-1}\right)\end{array}$ & $\mathrm{X}_{\mathrm{c}}^{\prime}(\%)$ \\
\hline $100 / 0$ & -- & -- & -- & 120 & 130 & $151 \pm 3$ & -- & 51.5 \\
\hline $50 / 50$ & 56 & $47 \pm 1$ & 60.3 & 114 & 121 & $75.2 \pm 4.2$ & 75.5 & 51.3 \\
\hline $35 / 65$ & 56 & $74 \pm 4.5$ & 78.4 & 111.5 & 118 & $56.7 \pm 2.3$ & 52.9 & 55.3 \\
\hline $25 / 75$ & 56 & $89 \pm 3.5$ & 90.4 & 110.5 & 116 & $42 \pm 3.9$ & 37.8 & 57.3 \\
\hline $0 / 100$ & 56.8 & $121 \pm 4$ & -- & -- & -- & -- & -- & -- \\
\hline
\end{tabular}

$\mathrm{T}_{\mathrm{m} \text { peak }}, \Delta \mathrm{H}_{\mathrm{m}}$ and $\Delta \mathrm{H}_{\mathrm{m} \delta}$ are the melting peak temperature, observed melting enthalpy and calculated melting enthalpy of $\mathrm{H}-\mathrm{PW}$ respectively. $\mathrm{T}^{\prime}{ }_{\mathrm{m} \text { peak }}, \Delta \mathrm{H}_{\mathrm{m}}$ and $\Delta \mathrm{H}^{\prime}{ }_{\mathrm{m} \delta}$ are the melting peak temperature, observed melting enthalpy and calculated melting enthalpy of the HDPE, respectively. $X^{\prime}{ }_{c}$ is the crystallinity of the blends.

Table 2

\begin{tabular}{|c|c|c|c|c|c|c|c|c|}
\hline $\begin{array}{c}\text { hv-HDPE/ } \\
\text { L-PW }\end{array}$ & $\begin{array}{c}T_{\text {m peak }} \\
\left({ }^{\circ} \mathrm{C}\right)\end{array}$ & $\begin{array}{c}\Delta \mathrm{H}_{\mathrm{m}} \\
\left(\mathrm{J} \mathrm{g}^{-1}\right)\end{array}$ & $\begin{array}{l}\Delta \mathrm{H}_{\mathrm{m} \delta} \\
\left(\mathrm{J} \mathrm{g}^{-1}\right)\end{array}$ & $\begin{array}{c}T^{\prime} \text { m onset } \\
\left({ }^{\circ} \mathrm{C}\right)\end{array}$ & $\begin{array}{c}T^{\prime} \text { m peak } \\
\left({ }^{\circ} \mathrm{C}\right)\end{array}$ & $\begin{array}{l}\Delta \mathrm{H}^{\prime} \mathrm{m} \\
\left(\mathrm{J} \mathrm{g}^{-1}\right)\end{array}$ & $\begin{array}{l}\Delta \mathrm{H}^{\prime} \mathrm{m} \delta \\
\left(\mathrm{J} \mathrm{g}^{-1}\right)\end{array}$ & $X^{\prime}{ }_{c}(\%)$ \\
\hline $100 / 0$ & -- & -- & -- & 120 & 130 & $151 \pm 3$ & -- & 51.5 \\
\hline $60 / 40$ & 26 & $43 \pm 3$ & 49.2 & 112 & 120 & $80 \pm 6$ & 90.6 & 47.2 \\
\hline $50 / 50$ & 25 & $61 \pm 2$ & 61.5 & 110 & 118 & $78 \pm 8$ & 75.5 & 53.2 \\
\hline $35 / 65$ & 25 & $70 \pm 5$ & 79 & 109 & 117 & $61 \pm 5$ & 54 & $59 . .5$ \\
\hline $0 / 100$ & 24 & $123 \pm 7$ & -- & -- & -- & -- & -- & -- \\
\hline
\end{tabular}

$\mathrm{T}_{\mathrm{m} \text { peak }}, \Delta \mathrm{H}_{\mathrm{m}}$ and $\Delta \mathrm{H}_{\mathrm{m} \delta}$ are the melting peak temperature, observed melting enthalpy and calculated melting enthalpy of L-PW, respectively. $\mathrm{T}^{\prime} \mathrm{m}$ peak, $\Delta \mathrm{H}_{\mathrm{m}}^{\prime}$ and $\Delta \mathrm{H}^{\prime}{ }_{\mathrm{m} \delta}$ are the melting peak temperature, observed melting enthalpy and calculated melting enthalpy of the HDPE, respectively. $\mathrm{X}^{\prime}{ }_{\mathrm{c}}$ is the crystallinity of the blends.

Table 3

\begin{tabular}{cccccccc}
\hline $\begin{array}{c}\text { hv-HDPE/ } \\
\mathrm{H}-\mathrm{PW}\end{array}$ & $\begin{array}{c}\mathrm{T}_{\mathrm{c} \text { peak }} \\
\left({ }^{\circ} \mathrm{C}\right)\end{array}$ & $\begin{array}{c}\Delta \mathrm{H}_{\mathrm{c}} \\
\left(\mathrm{J} \mathrm{g}^{-1}\right)\end{array}$ & $\begin{array}{c}\Delta \mathrm{H}_{\mathrm{c} \delta} \\
\left(\mathrm{J} \mathrm{g}^{-1}\right)\end{array}$ & $\begin{array}{c}\mathrm{T}^{\prime} \text { c onset } \\
\left({ }^{\circ} \mathrm{C}\right)\end{array}$ & $\begin{array}{c}\mathrm{T}^{\prime} \mathrm{c} \text { peak } \\
\left({ }^{\circ} \mathrm{C}\right)\end{array}$ & $\begin{array}{c}\Delta \mathrm{H}^{\prime} \mathrm{c} \\
\left(\mathrm{J} \mathrm{g}^{-1}\right)\end{array}$ & $\begin{array}{c}\Delta \mathrm{H}^{\prime} \mathrm{c} \delta \\
\left(\mathrm{J} \mathrm{g}^{-1}\right)\end{array}$ \\
\hline $100 / 0$ & -- & -- & -- & 114.2 & 110.5 & $143 \pm 4$ & \\
$50 / 50$ & 45 & $51 \pm 2.2$ & 64 & 106.5 & 104 & $75 \pm 4.2$ & 71.5 \\
$35 / 65$ & 44 & $79 \pm 4.1$ & 83.2 & 105 & 102 & $57 \pm 2.3$ & 50 \\
$25 / 75$ & 45 & $94 \pm 4.1$ & 96 & 103 & 100.5 & $42 \pm 3.9$ & 35.8 \\
$0 / 100$ & 45 & $128 \pm 3.8$ & -- & -- & -- & -- & -- \\
\hline
\end{tabular}

$\mathrm{T}_{\mathrm{c} \text { peak, }} \Delta \mathrm{H}_{\mathrm{c}}$ and $\Delta \mathrm{H}_{\mathrm{c} \delta}$ are the crystallisation peak temperature, observed crystallisation enthalpy and calculated crystallisation enthalpy of $\mathrm{H}-\mathrm{PW}$, respectively. $\mathrm{T}^{\prime}{ }_{c \text { peak }}, \Delta \mathrm{H}^{\prime}{ }_{c}$ and $\Delta \mathrm{H}^{\prime}$ co are the crystallisation peak temperature, observed crystallisation enthalpy and calculated crystallisation enthalpy of the blends, respectively. 
Table 4

\begin{tabular}{cccccccc}
\hline $\begin{array}{c}\text { hv-HDPE/ } \\
\text { L-PW }\end{array}$ & $\begin{array}{c}\mathrm{T}_{\mathrm{c} \text { peak }} \\
\left({ }^{\circ} \mathrm{C}\right)\end{array}$ & $\begin{array}{c}\Delta \mathrm{H}_{\mathrm{c}} \\
\left(\mathrm{J} \mathrm{g}^{-1}\right)\end{array}$ & $\begin{array}{c}\Delta \mathrm{H}_{\mathrm{c} \delta} \\
\left(\mathrm{J} \mathrm{g}^{-1}\right)\end{array}$ & $\begin{array}{c}\mathrm{T}^{\prime} \mathrm{c} \text { onset } \\
\left({ }^{\circ} \mathrm{C}\right)\end{array}$ & $\begin{array}{c}\mathrm{T}^{\prime} \mathrm{c} \text { peak } \\
\left({ }^{\circ} \mathrm{C}\right)\end{array}$ & $\begin{array}{c}\Delta \mathrm{H}^{\prime} \mathrm{c} \\
\left(\mathrm{J} \mathrm{g}^{-1}\right)\end{array}$ & $\begin{array}{c}\Delta \mathrm{H}^{\prime} \mathrm{c} \delta \\
\left(\mathrm{J} \mathrm{g}^{-1}\right)\end{array}$ \\
\hline $100 / 0$ & -- & -- & -- & 114.2 & 110.5 & $143 \pm 4$ & \\
$60 / 40$ & 20 & $40 \pm 5$ & 52 & 113 & 109.5 & $82 \pm 4$ & 85.8 \\
$50 / 50$ & 19.5 & $56 \pm 4$ & 65 & 112.5 & 109 & $62 \pm 6$ & 71.5 \\
$35 / 65$ & 19.5 & $64 \pm 5$ & 84.5 & 112 & 108.5 & $53.6 \pm 4$ & 50 \\
$0 / 100$ & 22 & $130 \pm 8$ & -- & -- & -- & -- & -- \\
\hline
\end{tabular}

$\mathrm{T}_{\mathrm{c} \text { peak }}, \Delta \mathrm{H}_{\mathrm{c}}$ and $\Delta \mathrm{H}_{\mathrm{c} \delta}$ are the crystallisation peak temperature, observed crystallisation enthalpy and calculated crystallisation enthalpy of L-PW, respectively. $\mathrm{T}^{\prime}{ }_{\mathrm{c} \text { peak }}, \Delta \mathrm{H}^{\prime}{ }_{\mathrm{c}}$ and $\Delta \mathrm{H}^{\prime}{ }_{\mathrm{c} \delta}$ are the crystallisation peak temperature, observed crystallisation enthalpy and calculated crystallisation enthalpy of the blends, respectively. 
Figure 1
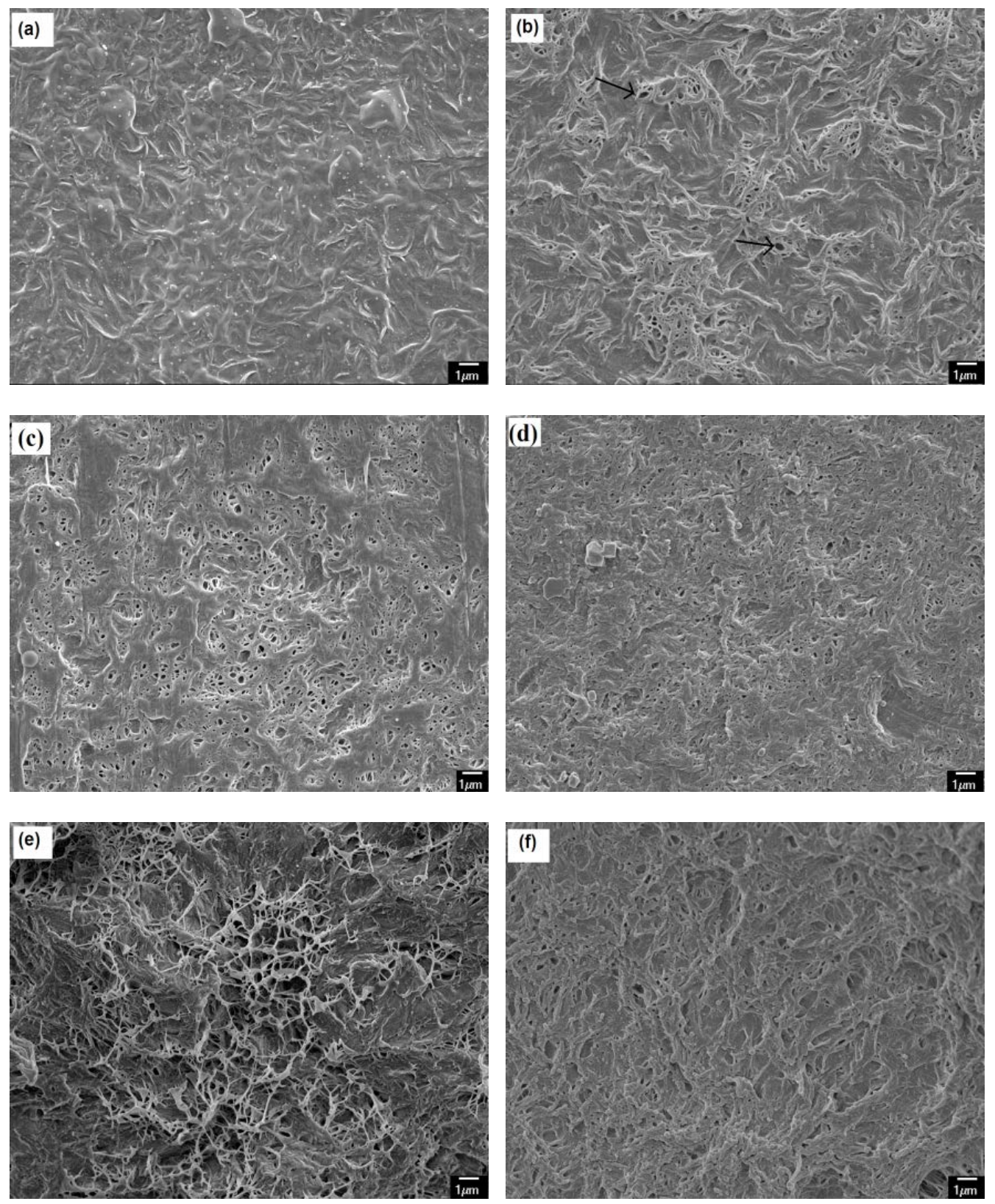
Figure 2

(a)

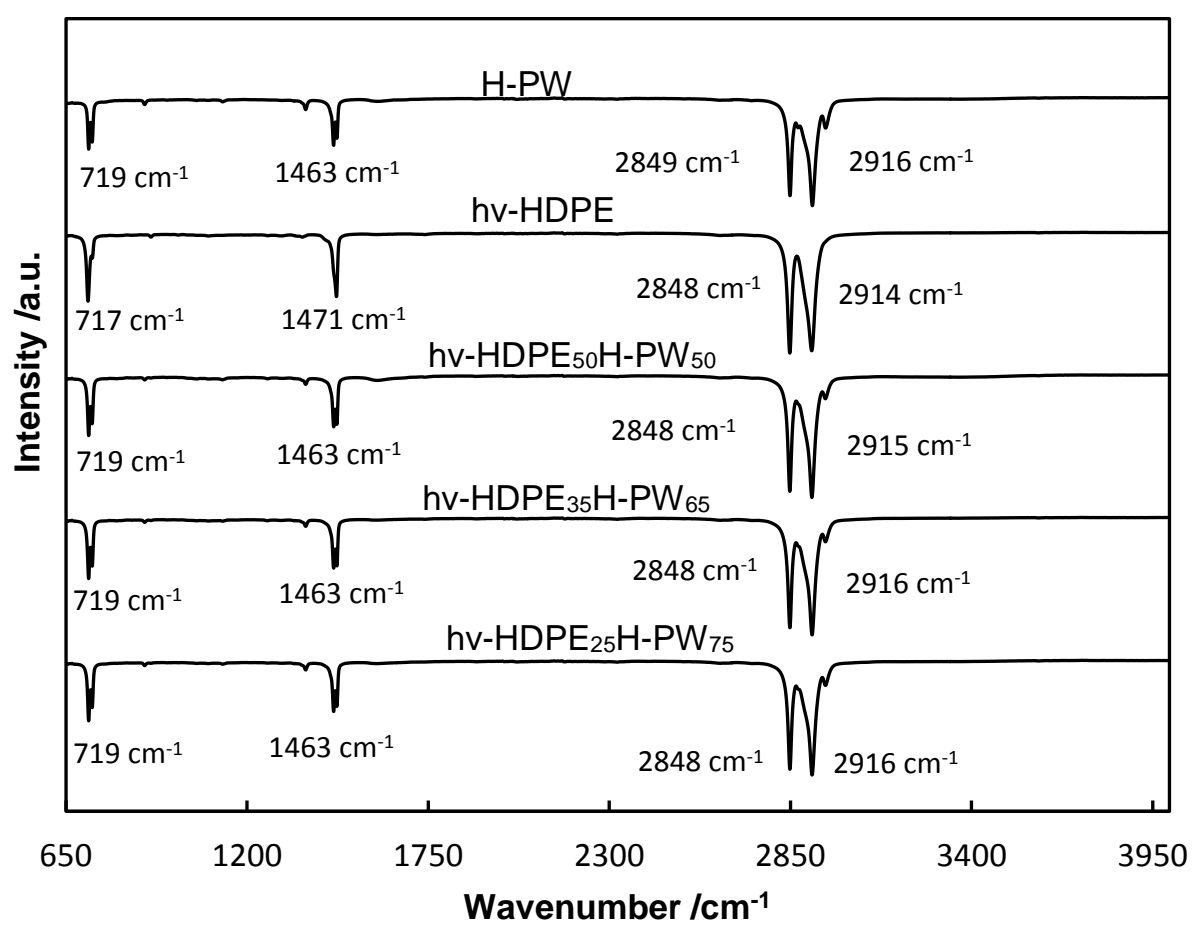

(b)

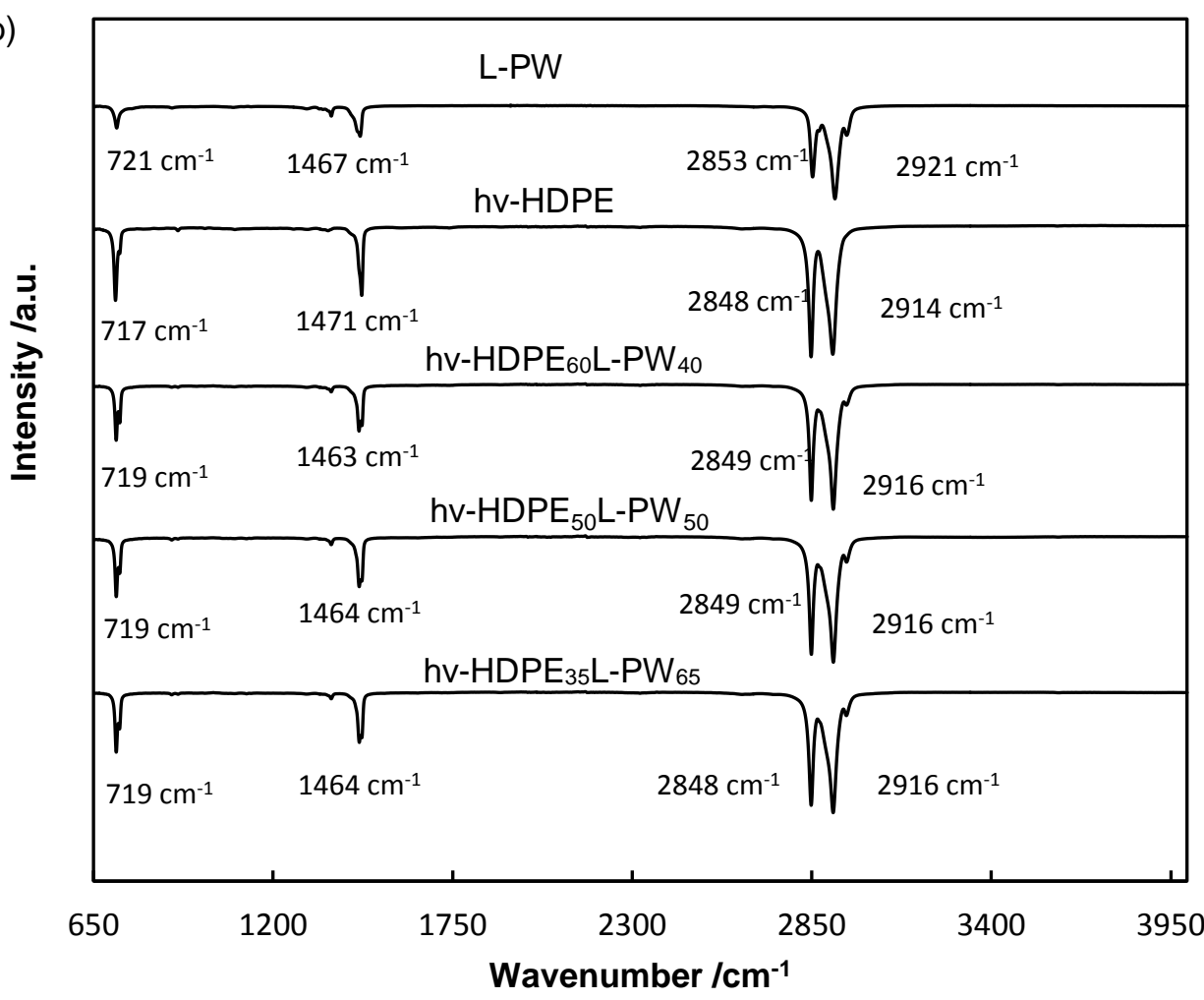


Figure 3
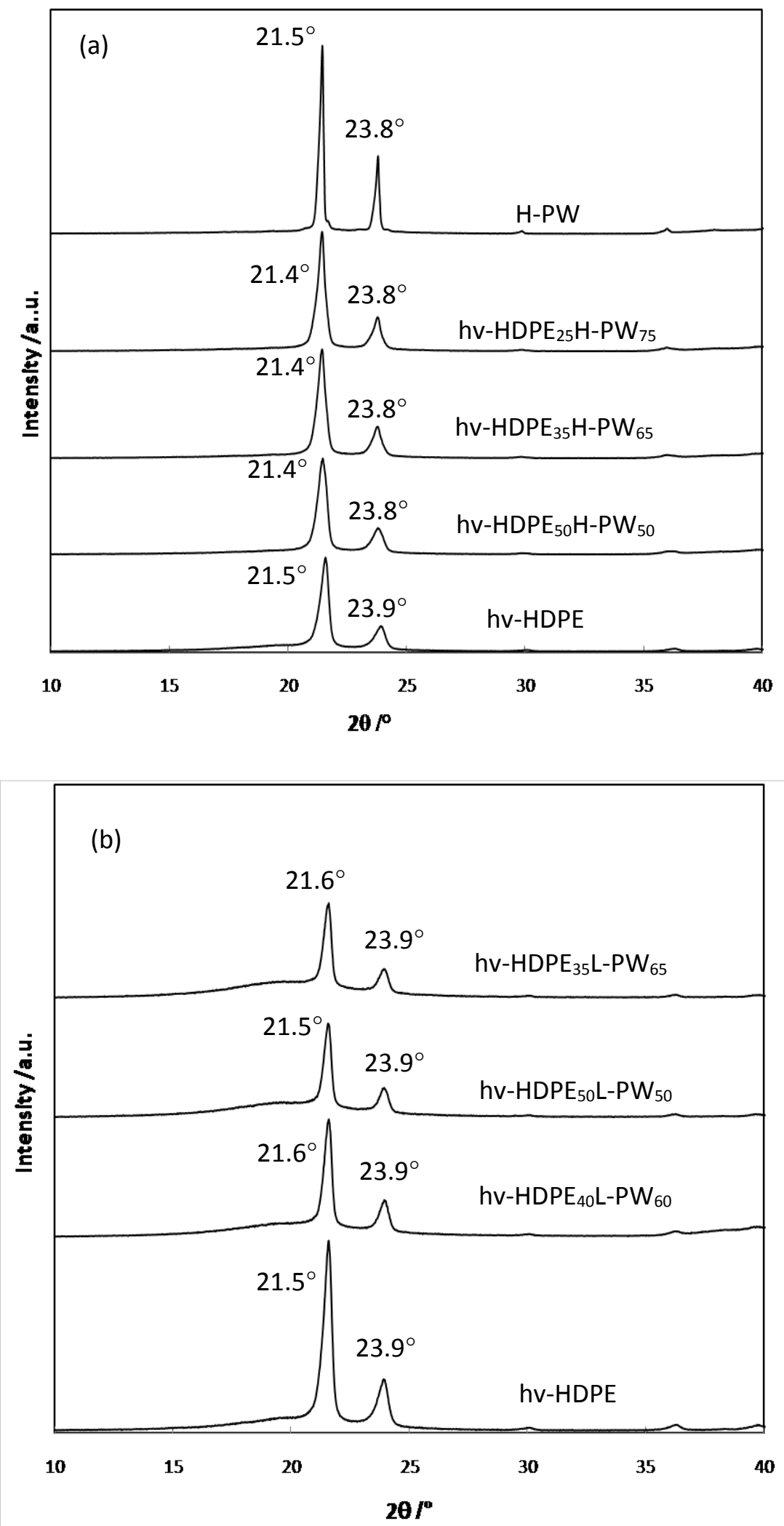
Figure 4
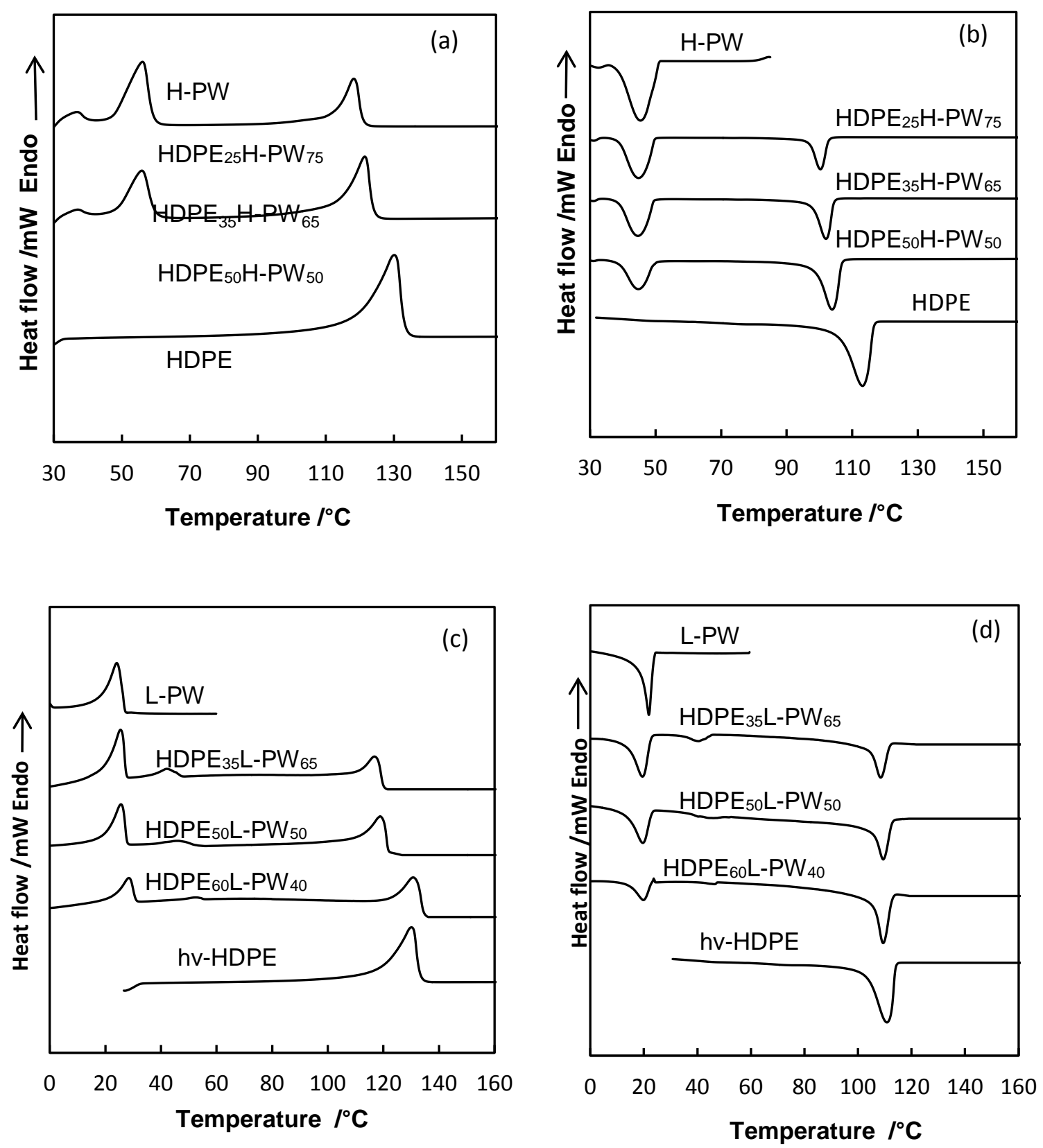
Figure 5
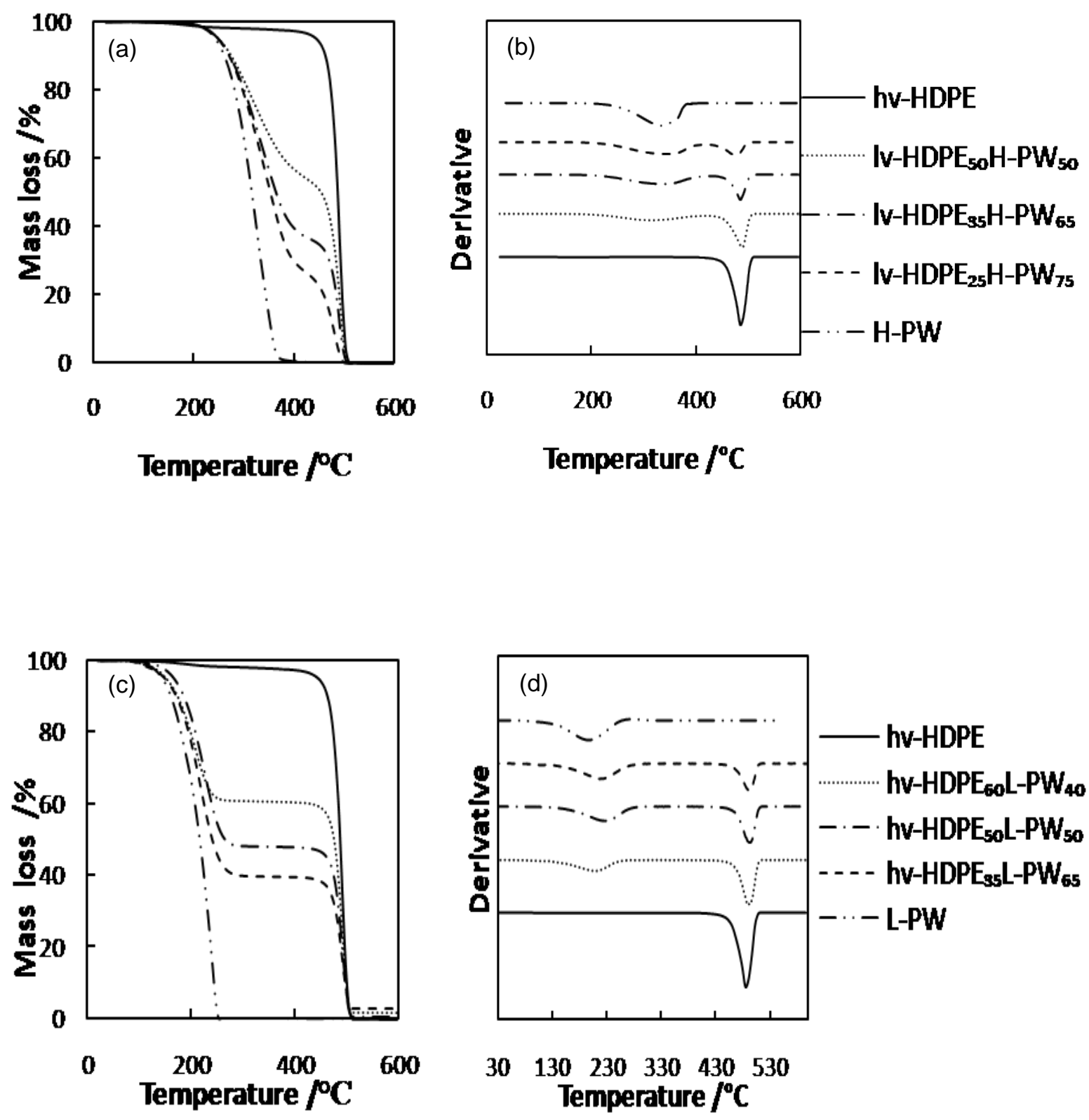
Figure 6
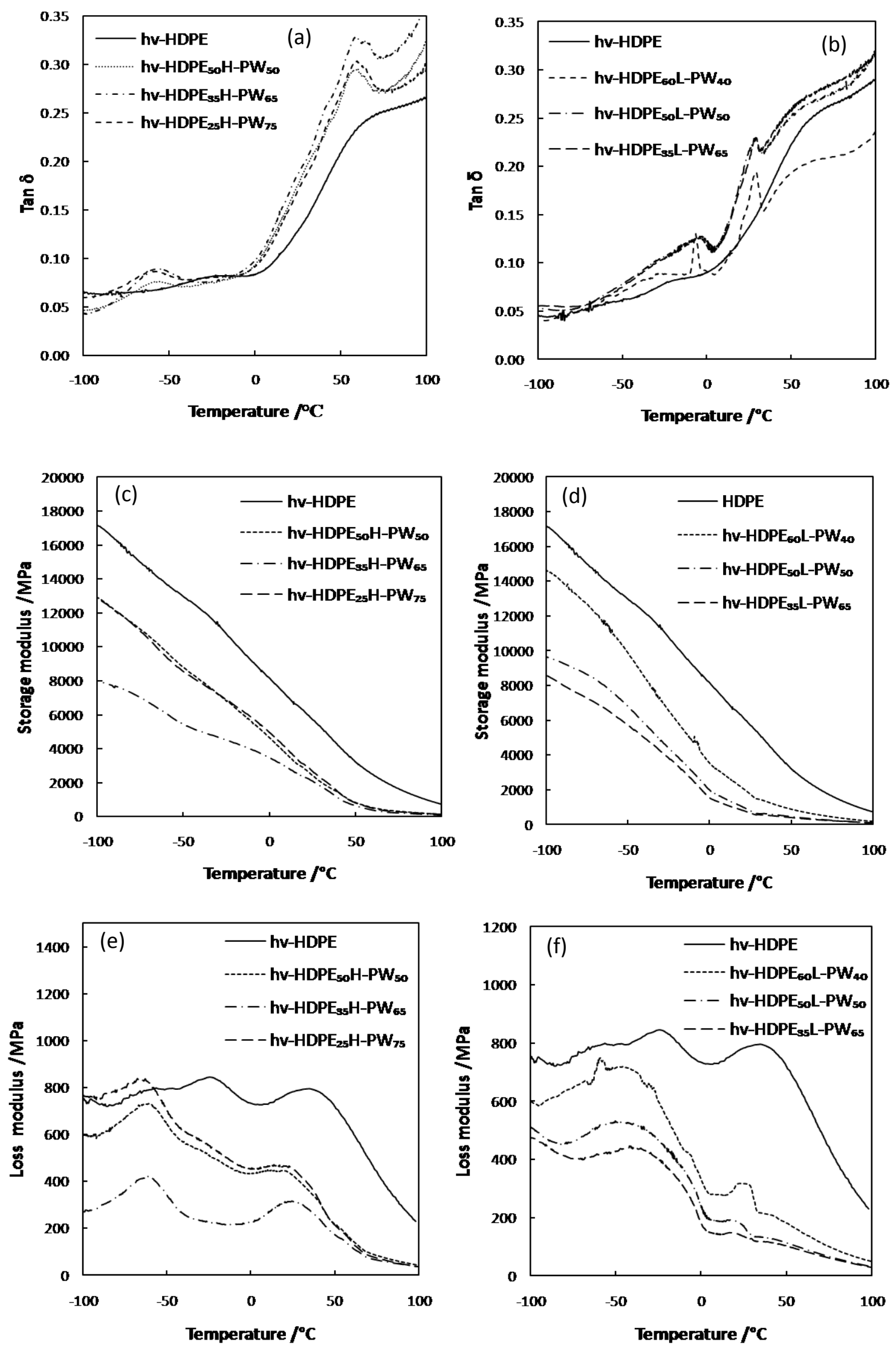
Figure 7
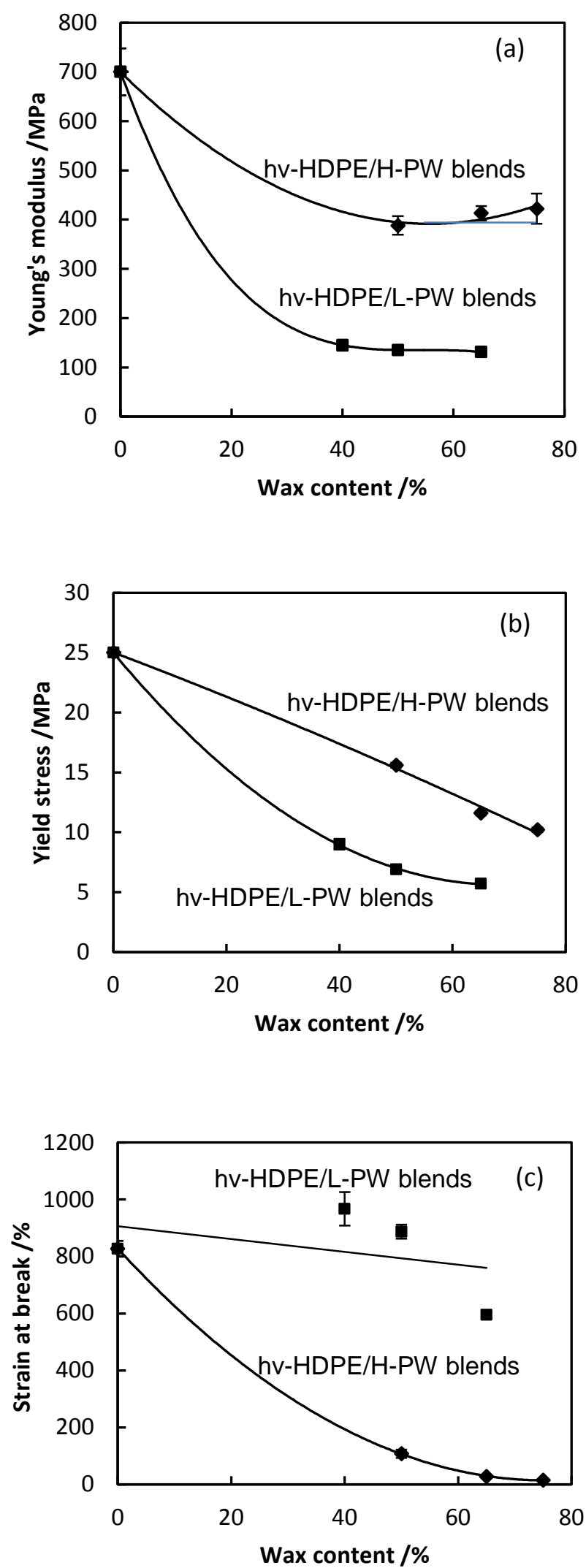
Figure 8
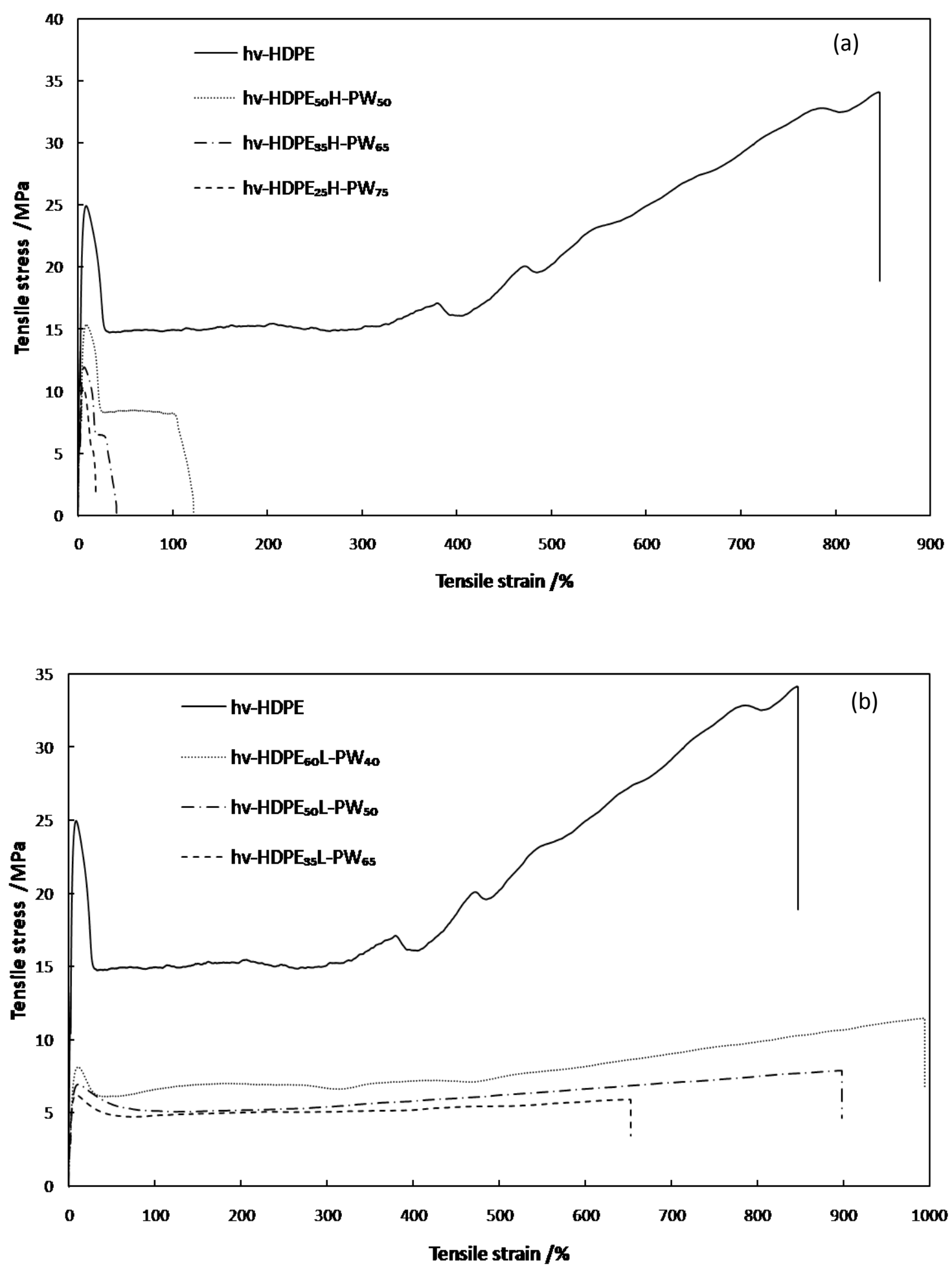
Figure 9
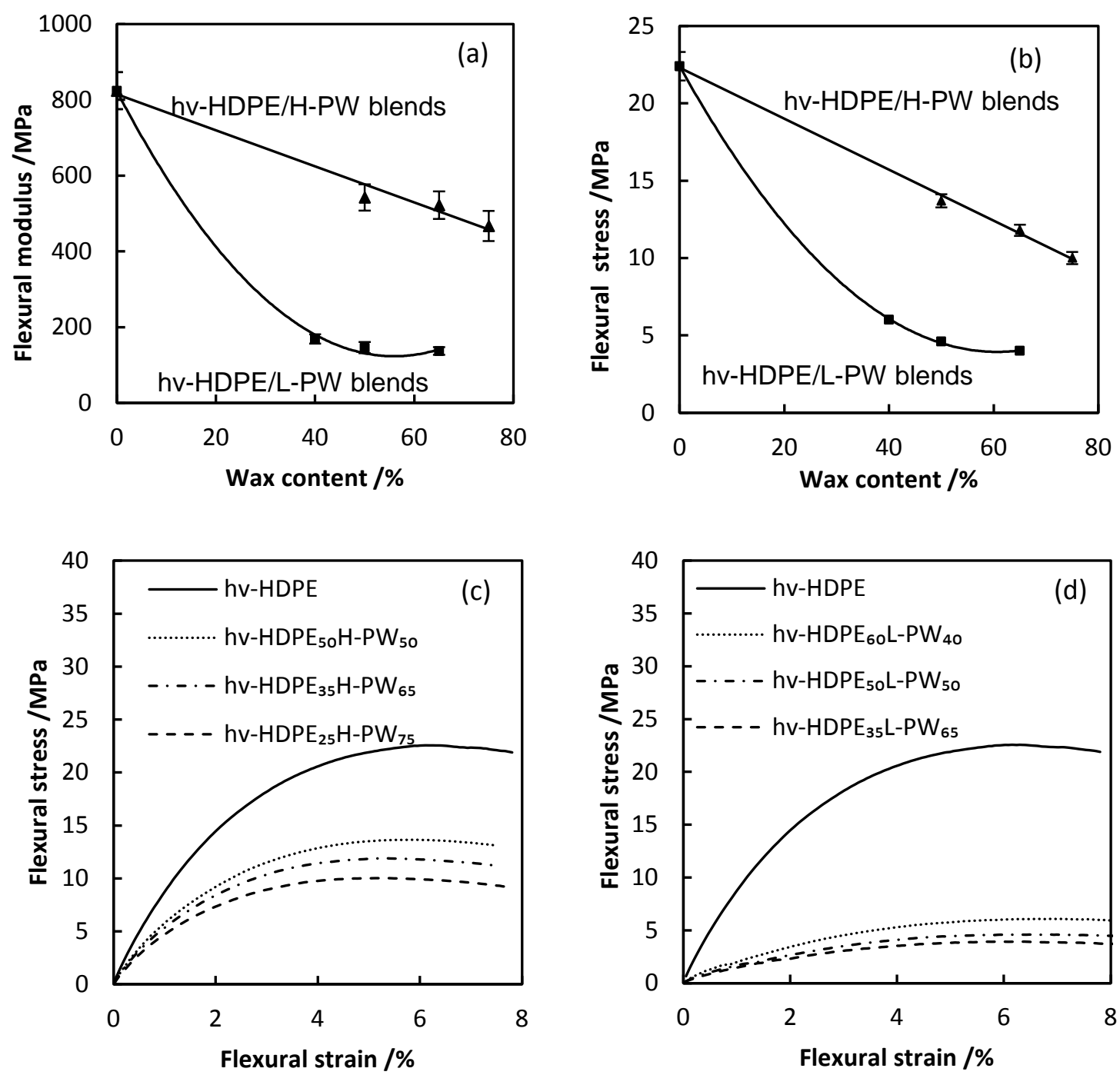
Figure 10
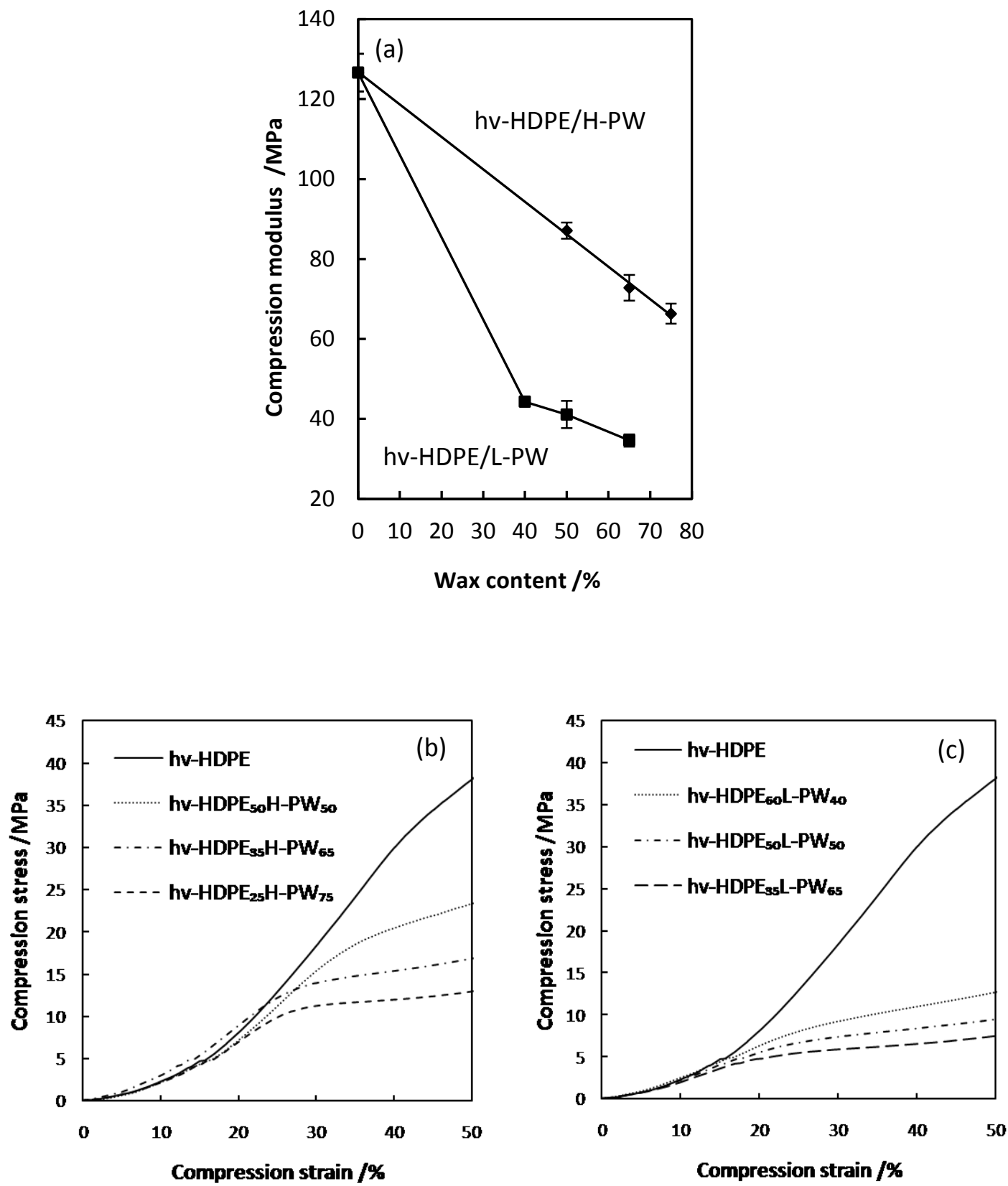
Figure 11
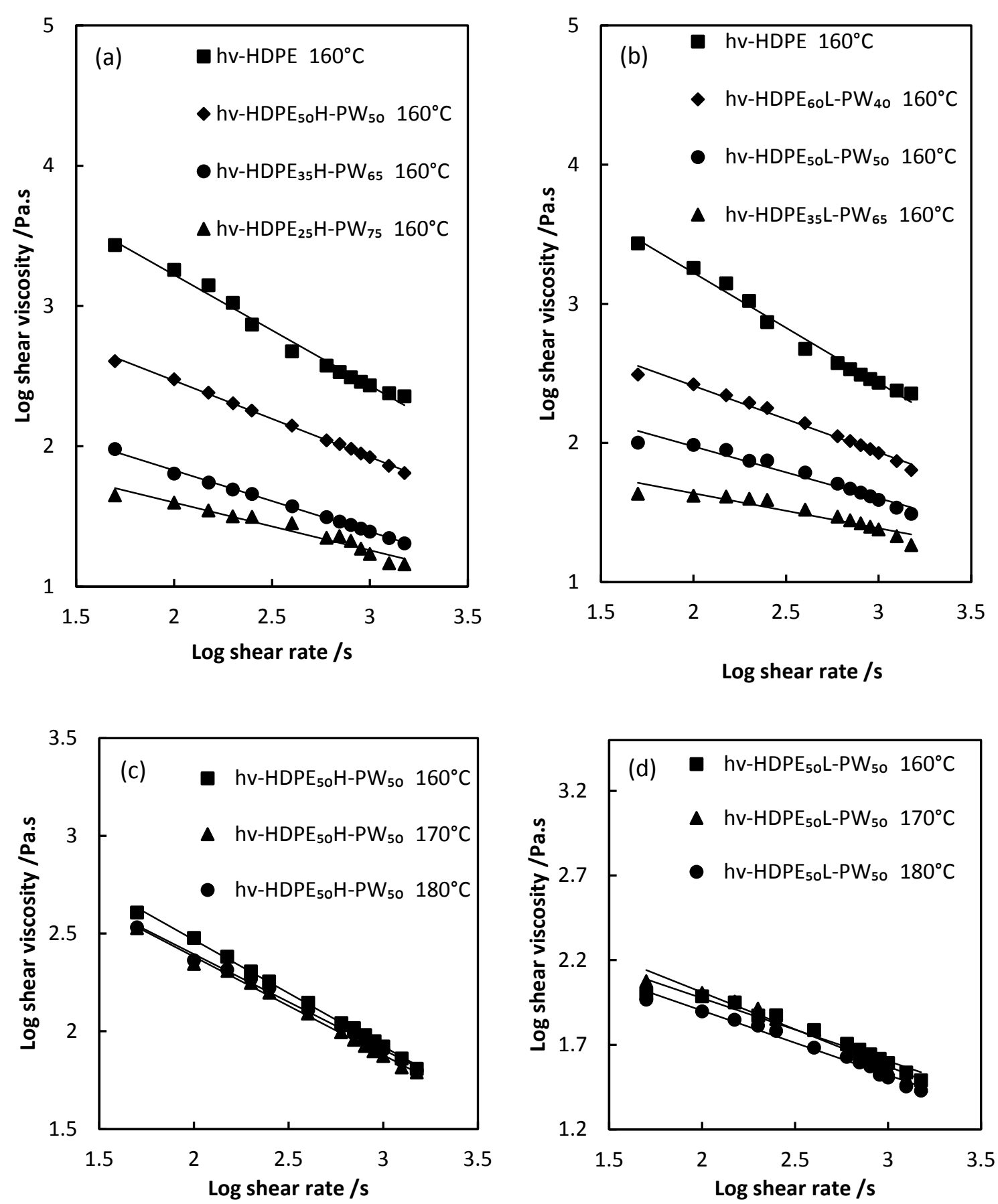
Figure 12
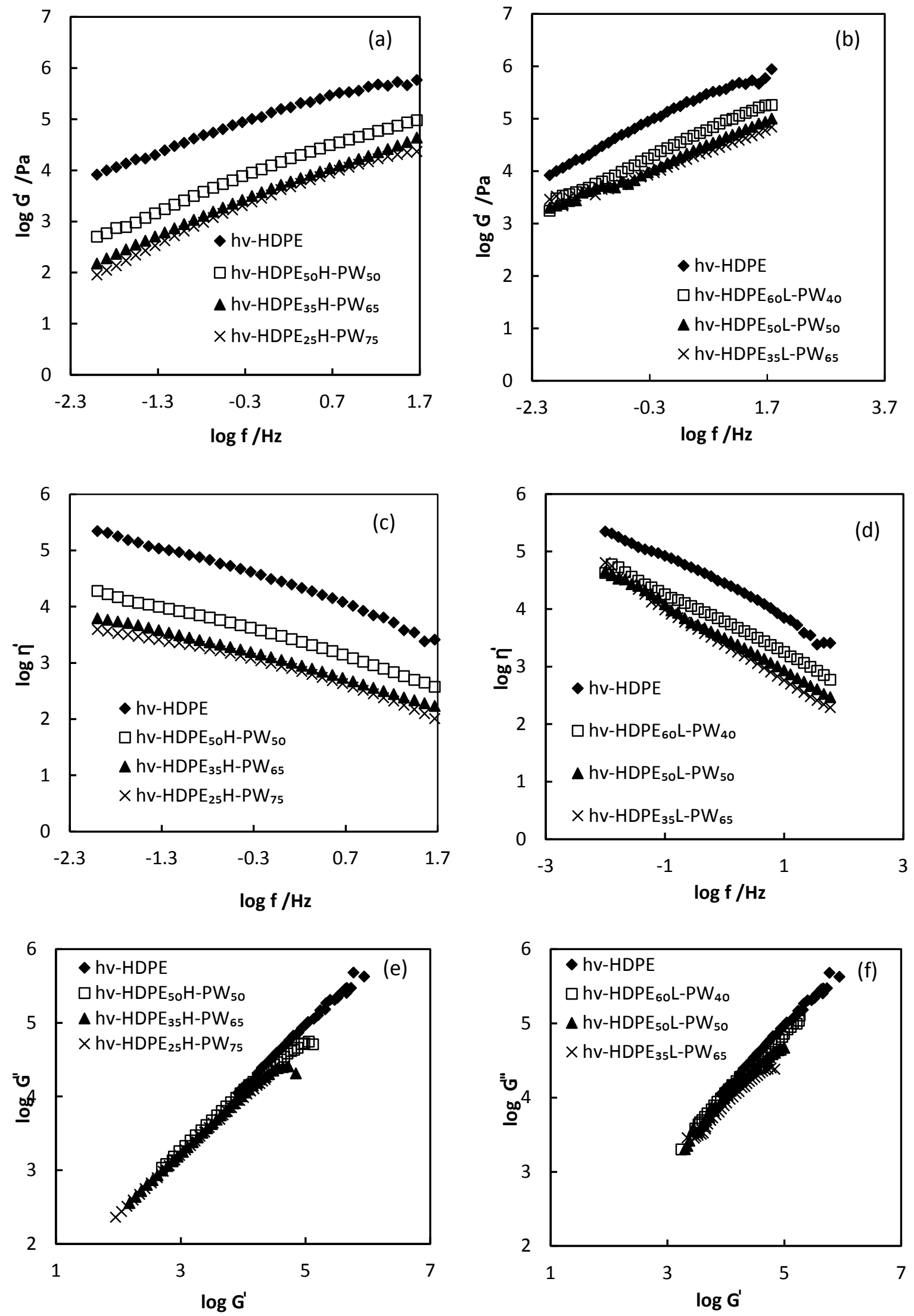